\title{
CRIMINAL RESPONSIBILITY OF EPILEPTICS, AS ILLUSTRATED BY THE CASE OF DAVID MONTGOMERY.
}

BY M. G. ECHEVERriA, M. D.

The cardinal points in treating epileptic insanity are to acquire a knowledge of its true nature, and then to establish the mode in which the mental condition of the individual is perverted or affected by its paroxysms. Alienists of eminent ability have considered this question, and many essays have been already published on the sulject. It may, therefore, be asked, why should this one be presented? Because the medico. legal enquiries concerning the responsibility of epileptics are still conducted in a manner very different from that in which they should be, as is illustrated by the caso here examined. Those who have more confidence in speculative reasoning than in facts, fancy that the moral perversion, the extreme morbid susceptibility with which the character of epileptics is so deeply stamped, has no necessary relation to their dreadful malady. Consequently, theories suitable to the inter. est of the party who calls them, and often based on distorted scientific principles, are presented by medical witnesses in the most unbesitating manner, and suffered to influence the decisions of Courts of Justice, even though these witnesses, with equal assurance and selfsufficiency, declare their want of practical experience with e jilepsy or insanity, while not hesitating to advance expet opinions on the legal accountability of epileptics and their mental state. In other words, as 
Professor Ordronaux so truthfully says in his excellent work "On the Jurisprudence of Insanity," (p. 165,) "The effeets of disease upon mental capacity are wholly ignored or repudiated when an expert in mental capacity is summoned to testify, but completely recognized and admitted where physicians and nurses, who are not experts, are called as witnesses. This may pass for metaphysics, but it certainly is not law, since it violates both reason and justice, and ignores the essential element of experience which constitutes a skilled witness." Let us, however, hope that the enlightened justice of our legislators will so appreciate the existing evil as to determine upon wiser and more equitable laws concerning the standard of qualifications of experts in insanity, and the manner in which their testimony should be given in order to aid the judgment of juries.

David Montgomery, a cartman, now twenty-one years of age, was indicted for killing his wife on the morning of the 13th of November, 1870. He inflicted upon the left side of her head, a penetrating wound with an axe, from which she died on the following day. The crime was committed in the city of Rochester, N. Y., where the trial took place, on the 17th of May, 1871, in the Court of Oyer and Terminer. I will here present an abstract of the leading facts in evidence as transcribed in the certified record of the trial.

Hereditary predisposition to insanity existo in the highest degree in David Montgomery. His father suffers from a rush of blood to the head, and dizziness, which "makes him lean against the fence when it occurs." His paternal great-grandfather and grandfather, and his uncles, in the same line, lave been affected with "a rush of blood to the head which makes they. fall." A paternal uncle and his sister died insane; 
brother of his paternal grand-mother died insane in the Lunatic Asylum at Berwick-on-Tweed. One of his father's brothers is insane, and in the $\Lambda$ sylum at Rochester, Monroe County, and finally, his mother died paralyzed. David Montgomery was born with a large head, so large, that the midwife thought he was affected with "water in the brain." He was subject during his infancy and childhood to diurnal and nocturnal characteristic epileptic fits, and from that age was habitually spoken of and regarded by his family as disordered in mind; they called him "crazy" or "Daft Davy." $\mathrm{He}$ has besides been troubled since his infancy with a dis. charge from the right ear, and beadache. When eight sears old he fell from a peddler's wagon, apparently in an epileptic fit, and was taken up insensible, with a wound on the left side of the head, about half an inch long. He received another severe injury of the head, three or four years ago, while he was drawing gravel, on the same side where he had been cut previously, and was confined to bed five days. He had had nocturnal fits, spots of blood having been observed several times on his pillow. He has beaten the wall on frequent $o$. casions in the night time, saying "these imps can't keep making faces at me, and me not do anything to them ;" he would get out of bed and be standing up, on occasions of this kind, or would strike his brother with whom he slept. Being subject to frequent and violent headache, when fifteen or sixteen years of age, on one occasion while thus suffering he was in his father's house exclaiming: "God was above me once, but I am above him now, why are you blind?" and then struck his father, but on the following lay had no recollection of the matter. About that same time he was found, at sunrise, in an alley beside the house, lying under a wagon with a Newfoundland dog, and apparently not 
[January,

knowing how he had come there. At the age of eighteen Montgomery was married to a vile, dissolute woman. How he was led into such an unfortunate marriage does not appear in evidence; he was a hard working, industrious boy, attended a Methodist Sunday Schosl, and his father, who kept a store for years, says that he never saw him drink spirits; no evidence whatever indicates that he was intemperate. In the fall of 1870, while in conversation with Joseph $\mathrm{H}$. Duncalf, three days after his wife had left him, he was in great grief, and Duncalf, to change the subject, asked him about a horse which he had sold him. Montgomery replied that-he was the strongest horse he ever owned, and then proposed to pull up a post that all the men in the house could not pull up. He threw his arms around the post and pulled it with all his might; his face looked red, and his eyes large, then he walked away. In October, 1870, he could not sleep at times, and was once seen by Catharine Donovan in great mental agony, crying and sobbing in the most lamentable manner. He would get up late at night to go to the barn, and when Catharine Donovan would ask him "what was the matter with him," he said that he could not sleep with the headache, and that he might as well be up as in bed. On different occasions, while watering the horses, his brother Robert saw him drop the pail, with his moath and arms twitching, or again saw him looking for a currycomb or brush, when he had it in his hand, and talk to himself entirely un. conscious of what he was doing. One of his neighbors saw him in the open street driving his horse and cart up to the sidewalk, laughing, crying, wringing his hands and rubbing his forehead. $\Lambda$ bout this same time, after speaking to his brother Andrew about the baby and its mother, he appeared to get wild and ex- 
cited; thereupon he leaned over a gate, which was near by, and said to his brother, "you think uncle Dave is strong, don't you?" "Yes," replied the brother, and he answered, "He is not half so strong as me," and taking hold of a post, he lifted it as hard as he could until his face was perfectly red. He then held out his hands exclaiming: "There, do you see that, did you think I was as strong as that; I could lift the corner of the house as well."

On Monday evening, before the homicide, he came into his father's barn, bare headed, and rubbing his hands, he told his father to repeat the Lord's prayer "quick," "quick," which he commenced himself, and repeated two or three times in an unintelligible manner. The next day, Tuesday, in the forenoon, he had an epi. leptic fit, as testified to by his father and Catharine Cuthbert. He became very much distressed on Thursday night, believing himself chased by five men and the devil; he then wanted his father and one of his brothers to go out with him, which they did to quiet him. On Friday afternoon, while in his cart, he had a fit, his head was leaning back, he was licking his lips, mumbling, muttering to himself, and rubbing his head. A lady having engaged him at this moment to move her trunks, asked him how much he charged; he said "two dollars," but she was willing to pay only one dollar, and he replied, that he would do it. His wife and mother-in-law then came to the cart : he was apparently asleep, his wife shook him, and asked him if he had been up the night previous. He opened his eyes wildly, and she asked him if he would go down that night, and he said-yes. Thereupon they went off; he returned to his former position, and Philip Bachs, who testifies to these facts, stepped up and remarked to him that it was time to go after the lady's trunk, and that Vor. XXIX.-No. III.-(; 
if he did not go, he (Bachs) would go. "Montgomery jumped up, hit his mare a cut, and drove up the street," but came back again inquiring: "Bachs, who was that woman, and where in $\mathrm{h}-\mathrm{l}$ am I to go?"

On Saturday morning-eve of the homicide-his father saw him bring the horse out of the barn, about seven o'clock, hitch him to the cart, then unhitch him, take him to the barn, and let him stand there five minutes; he also saw him walk around the cart, rubbing his hands, before bringing back the horse to hitch him up again, without answering his father or taking notice of what he remarked when he told him the second time not to put the horse to the cart, that he had better leave him in the barn. About four or five o'clock in the afternoon he spoke in a senseless manner upon different things; between seven and eight o'clock in the evening he became as wild as his father ever saw him. He then came in and told his father that, there was a man outdoors who wanted to see him; he turned, wheeled around and went out. About eight o'clock he still labored under delusions; he then asked Robert Y. Duncalf to stay all night with him, saying that he was alone; he looked wild at the time, more so than he did at noon, when he was particularly noticed also by Duncalf. While making the above request he stood at the door of the barn, where he kept his horse. On this very day, David Montgomery was met in the forenoon by Wm. White, his wife's uncle, whom he told that he had divided with his wife and taken the baby, nine months old, to his father's house. White reproached Montgomery for his conduct, and asked him if he could carry the baby to its mother. Montgomery at first refused, but afterwards said, "I don't care." Upon White's invitation, Montgomery accompanied him to sez his wife. She received them, and without much 
argument consented to go back to Montgomery if he would move from where he lived, which he agreed to do. They dined together, and in the afternoon White and Montgomery went to sell some chickens. Towards evening Montgomery spoke and said, "If she ever comes back to live with me again she'll never leave me." They met a boy, brother of Montgomery's wife, who told his uncle that he had got the baby down at his sister's. Montgomery naturally, and without anger, said to him, "I shall whip you for stealing my baby." The boy replied: "You told me I might bring it down and uncle told me so," and Montgomery remarked, "If I did not talk I should not say anything." White and Montgomery separated about dark, the latter going, as he then stated, to take care of his horse. Between eight and nine o'clock in the evening Montgomery returned to his wife; she was absent then, but came in about nine o'clock. They talked together and she sat on his knee. When he got ready to go home, at about half-past eleven, he said, "Come, Mary, let's go home." She replied, "Let's all stay here to-night, and we'll make up an extra bed on the floor." "I ain't took care of my horse yet, and I would go ten miles to take care of my horse." Then she said, "Uncle, you go home with him," but Montgomery answered, "No ; I want you should go, and then come up to-morrow morning." White advised his niece to go home with her husband, and offered to come up in the morning. Thereupon Montgomery, his wife and the baby, carried by the former, went home, according to White's testimony, who parted with them thinking "it was all peace and harmony" between them.

No evidence disproves the testimony of Montgomery's father and Christine Cuthbert, showing that David Montgomery took the ax to split up some wood on the 
Thursday night previous to the homicide, between one and two o'clock, and did not return it to his father's house. There is no evidence beyond Montgomery's own statement, any more entitled to faith than are his delusions, touching his real mental condition, or indeed what occurred on the night of Saturday, when he, though he had been kept awake for several nights, did not "sleep a wink," and must have been necessarily enveloped in the clouds of mental disorder attending the undeniably repeated epileptic attacks he had experienced throughout the week. Nor is there any proof of his having quarrelled with his wife after they retired "in peace and harmony," whereas it is manifest that she was sound asleep when he struck her, and Montgom. ery, as it may be seen hereafter, further acknowledges that they had sexual intercourse during the night.

Montgomery made no attempt to conceal his crime, or the murderous weapon. After inflicting the mortal blow upon his wife's head, he rushed out to the barn with a razor, pursued by a brother, who happened to see him, and afterwards by his father, to whom he declares that he has killed his wife and wants to kill himself, and, in their struggle to prevent it, he inflicted slight cuts on his throat. Then, upon his father's diraction, he wınt with his brother to the police office, muttering and rubbing his head. On the way he encountered James Hunter, to whom he owed some money for feed, and being asked by him where he was going, he answered nothing but, "My father will pay you." At the Police Station he said that "his wife would be a whore, and that ho would rather see her dead than to be one, and for that reason he struck her." He asked besides to be allowed to attend her funeral.

The testimony of the chaplain to the jail, the Rev. Thaye: H. Coddin', is most important. He saw Mont- 
gomery a few hours after the homicide, between eleven and twelve in the morning, and he describes his appearance as follows:

"He was an entire stranger to me. I never had seen him to notice him from any other man. He was pointed out to me as a man who had killed his wife. I went to the bed and spoke to him, and he raised a little and did not regard me much. I thought I would speak, and put my hands on his head and spoke to him very kindly, and he looked up at me. I asked some other questions to call him out, and before this time I placed both hands upon his head. I saw his head was in a terrible excited state, and appeared livid. I kept both hands on his head, and asked questions until he answered, and I spoke about the unfortunate condition he.was in, and after a little while he began to relate what harl taken place, and began to talk a little more freely, as I asked hi:n, and told me the incidents. He commenced the story where he had the ax in his hand, and said that he struck her with it. I remonstrated with him, and he said it was because he loved her so well. In answer to the question why he struck her, he said, 'Why, because I loved her so well.' 'And after I struck her, I stooped down and kissed her.' I asked, 'It was not because you hated her?' 'No.' I asked why he struck her, and he said because she had run with other men, and he had spent that night in trying to get her to live with him, and she said she would not live with him, or any single man. He said he couldn't live unless she lived with him. He then told me some of the history of it, and how he had bren kept awake, and had not slept for several nights, and that night not a wink did he sleep. He said : 'I loved her so well I could not live without her, and all $I$ want is, that they will let me go to the grave with her, and come back and hang me.' I said : 'How could you strike her with the ax?' He said: 'I stood with the ax about five minutes looking at her, and seemed impelled to strike her, and though I did not want to, I had to strike the blow.'"

The alove interview with the chaplain lasted from fifteen to twenty minutes. Montgomery appeared in a terrible state of excitement; he seemed to be all on fire. Subsequent to this Sunday the chaplain has conversed familiarly with Montgomery, and has not at any 
time been able to obtain any other information in respect to the incidents of the homicide. I may further add, that on Sunday morning, between eight and nine o'clock, Jerome Rogers, a police detective, had a conversation with Montgomery, after he was locked up, and asked how he came to kill his wife. Montgomery said, "My temper got the upper hand of me." $\mathrm{He}$ also said, that after striking her he threw the ax down and kissed her. That his father and brother prevented him from cutting. his throat; that they advised him to give himself up; he ramarked he could have gone to Canada, but that he would have been arrested : ome time; and the last he spoke was to ask if he would be allowed to go to the funeral. Finally, about thres o'clock in the afternoon, John F. Rothgangle and Mr. Benjamin, of the Rochester Express, called to see Montgomery. He was lying on a couch, with his face down, apparently asleep. The jailor roused him up, and Rothgangle testifies:

"When he was roused, he turned up partially on his back. I asked if he knew me; he did not speak directly, neither did he say whether he knew me. I finally mentioned my name, and reached out my hand, and he spoke to ms and shook hands. I finally spoke to him and said, 'Where are you' and said he, 'I don't know; will you tell me where I am ?' I think I told him, 'You are in jail.' He then wanted to know why he was there. I didn't answer dircely. I think Mr. Beckwith (the jailor) and $\mathbf{M r}$. Benjamin asked how long he had been there, and what his age was, and he said a thousand years. From that, I think Mr. Beckwith told him his wife was dead, or had been killed, and he wanted to know who killed her, and he turned to the wall and rapped and said: 'Go away from me, you have bothered me long enough.' I think he was rather flushed in the face.'

The following is the report of the Commissioners appointerl to enquire into the mental condition of David Montgomery : 
"The undersigned, your Commission, appointed by the Honorable Court of Oyer and Terminer, held in the city of Rochester, February, 1871, hereby report that: they have examined David Montgomery, now under indictment for homicide, and held in the jail of Monroe county. From the evidence they have obtained, and from personal examination of said David Montgomery, they come to the following conclusions, to wit:

1st. That said Montgomery had infantile epilepsy, and that they have been able to hear of only three (3) convulsions since he was three years of age, viz. : one at seven years, one at eight years of age, and one on the Thursday preceding the homicide.

2d. They find that he had, on numerous occasions, exhibited the evidence of that form of epileptic attacks known as epileptic seizures, of petit mal and that at these times he exhibited maniacal excitement, with tendency to violence.

3d. They find on personal examination, from his physical and physiological condition, evidence of slight dementia.

4th. We desire to say that we believe the evidence of petit mal, and the peculiar physiognomy of dementia observed in him, to be evidence of a permanent epileptic condition.

5th. Our conviction of the permanence of this condition is strengthened by strong hereditary tendency to insanity, as proved by its existence in two uncles and an aunt, and still further removed, in a great uncle, who died insane.

E. M. MOORE, M. D., H. W. DEAN, M. D., JOHN P. GRAY, M. D.

I concur in the above statements and opinions, and conclusions. GEO. COOK, M. D.

We, the undersigned, in the absence of the other Commissioners, deem proper to add, that in our opinion, John David Montgomery, with the exception of the slight dementia alluded to, is not in a condition of constant insanity.

E. M. MOORE, H. W. DEAN.

It is proper to make a single remark on the addenda of Drs. Moore and Dean, in reference to the condition of insanity displayed by Montgomery. Dementia is a 
consecutive or rather closing stage of mental disease generally, and, if in this case, as the report of the Commission shows, it is the consequence of a permanent epileptic condition, whether slight or profound, it must constitute a permanent insanity. Dementia is characterized by feebleness and the abolition, more or less marked, of the sensitive, intellectual and voluntary faculties, as Pinel and others describe it, the judgment becoming thereby necessarily impaired. This condition therefore is one of constant insanity, though capable of existing in every degree.

Drs. Gray, Cook and Moore testified at the trial, that, upon their personal examination of the prisoner, and the facts elicited by the different witnesses, they believed that Montgomery was insane at the moment he murdered his wife. The contrary opinion was supported by Drs. F. H. Montgomery, John F. Whitbeck and Wm. A. Hammond.

Dr. Montgomery declared, that he had not made a special study of the subject of insanity; had never had occasion to treat medically a single patient for insanity; and his experience of epilepsy had been very limited. He had never been consulted in regard to David Montgomery; although he may possibly have prescribed for him as a physician in his father's family.

As Dr. Montgomery, by his own admission was not an expert in insanity, it is not necessary to repeat his testimony or further refer to it.

Dr. John F. Whitbeck did not develop any new fact and concurred in all the views expressed by Dr. Montgomery.

To Dr. Hammond the credit is due of assuming in the Montgomery trial, for the first time in the records of American Medical Jurisprudence, the position of amicus curice, to give his testimony both on behalf of 
the prisoner and of the people. It is not in my province, nor is it my wish, to enter into the legal objections to the surprise which so unexpected a course caused to the prisoner's counsel. No more legitimate, or higher position could be taken by a medical expert than that which leaves the mind unbiased and free to establish impartially the scientific principles that will decide the fate of a human being, whilst there is no room for doubt that, in the trial of David Montgomery, the jury rendered their verdict of guilty of murder in the first degree, upon the testimony of Dr. Wm. A. Hammond, which, on account of its importance is here reproduced in full.

Hammond, Dr. William A., sworn for the defendant, and examined by Mr. Martindale.

Q. Are you a practicing physician and surgeon?

A. I have been for twenty-three years.

Q. Where are you at present engaged ?

A. In the city of New York.

Q. Have you been subpœnaed here on the part of the people, or invited to come?

A. I have.

Q. Did you afterwards receive a request from me?

A. I received a request on the 12 th of May, requesting me to come on behalf of the prisoner, and I replied by telegraph that I had been written to by the people.

Q. You have been present on the trial ?

A. Since the opening of the defence.

Q. You have heard the description of the condition of the defendant since infancy?

A. I have.

Q. Give me your opinion of the attacks.

A. I am decidedly of the opinion that they were epileptic.

Q. State whether there is anything peculiar in the circulation or condition of the prisoner, as relating to epilepsy.

A. He had the peculiar turgid condition of the extremities which is met with in epilepsy sometimes, but which is not peculiar to the disease, and is not found in all cases. 
Q. What do you find his pulse?

A. One hundred and ten.

Q. How does that compare with other symptoms?

A. It indicates some derangement of his health, but not necessarily any affection of the brain or nervous system, unless that is his habitual condition. I have known many persons whose pulse was over a hundred, not usually, and my own is nearly that.

Q. Have you examined his ear ?

A. I examined it in conjunction with Dr. Cook.

Q. What did you see?

A. All that I could make out without a speculum is that there is a considerable moisture, and perhaps some pus about the tympanum, and some slight appearance of ulceration, but it was impossible to say what it was.

Q. Assume the existence of these epileptic convulsions from childhood, continuing down to Tuesday before the homicide; assume, also, affection of the ear with putrid discharge; assume that these conditions all occurred and existed in 1866 ; that there has been a continuance of severe headaches; that on one of these occasions he rises suddenly in the chair, walking back and forth, wringing his hands, exclaiming, "God was above me once, but I am above him now," and strikes his father a blow, and shortly after is unconscious of that act-state to me the mental condition of the man at the time these manifestations occurred.

A. At that time, admitting the truth of what you say, he must have been suffering from hallucination and delusion-that ought to have been entirely temporary and were entirely due to an epileptıc seizure.

Q. Assuming that on a subsequent occasion he is seen turgid in the face and suddenly struggling to lift a post solidly imbedded in the ground-what, in your opinion, was his condition at that time?

A. That of itself would scareely indicate anything unusual, unless $I$ am more distinctly informed as to the manner of its occurrence. He may have said it in a state of playfulness. If it is a serious thing, and he believed it, it is another evidence of delusion.

Q. Of insanity?

A. Not necessarily-because all delusions do not indicate insanity.

Q. Taking all these things in connection with your examination, state his condition then?

A. I think he was then in a state of mental aberration. 
Q. Assuming that on Monday night, before the homicide, when in a state of excitement and distress, he enters the barn where his father was, he tells his father to say the Lord's Prayer, quick, quick, and he is repeating it rapilly?

A. I make the same answer.

Q. Take the case of Thursday, where he came rushing into the father's house, saying he was pursued by five men and the devil?

A. The same.

Q. Is this conclusion assisted any by the facts that at this time he was suffering from great mental disturbance from adequate cause?

A. Yes, sir.

Q. Assuming these facts, state your opinion as to whether this prisoner is now suffering from cerebral disease.

A. I think he is.

Q. Do you recognize the fact, even with epilepsy, that a person may be insane, disassociated from epilepsy?

A. Yes, sir.

Q. Are these facts evilence of a condition of insanity, seizing a post solidly imbedded in the ground, and holding it out, as though it had been pulled up, and the other circumstances to which your attention has been called-Are these things all indications of insanity without epilepsy?

A. In the absence of any other possible cause, I should say, yes.

Q. Do you recognize the fact that when a person is suffering from cerebral disease, there are paroxysms of convulsions?

A. Yes, sir; but cerebral disease may exist without insanity.

Q. All these circumstances concurring, all preceding the homicide, in your opinion, was the prisoner sane or insanc before the event of which I speak?

A. Before the homicide, I should think he was in a conclition of permanent insanity. My idea is, that these delusions were the result of paroxysms of epilepsy, because I know that they very frequently lead to such manifestations. $\Lambda$ t each one of these periods of delusional excitement, it seemed he had suffered from a paroxysm of epilepsy, either of the grand or petit mal.

Q. State what proportion of epileptic cases are accompanied with insanity, so far as your observation extends?

A. With insanity, not many; very few-with obvious mental deterioration, fifty per cent. I lo not suppose a man may have one attack, without his mind suffering more or less, but that would be very slight, and ordinary observers would not observe it. It is 
possible for a man to have a thousand attacks and not affect him perceptibly to ordinary persons.

Q. What did the evidence of Bachs indicate?

A. That did not impress me as indicating much. I did not attach a great deal of importance to the ability of the witness to discriminate, and the prisoner not falling, would be decidedly against his having had an epileptic seizure.

Q. Might he have had an attack of petit mal ?

A. It is possible, but not conclusive to my mind, that he did. The great difficulty is this, that if that man was a patient of mine, and $I$ was inquiring into his mental condition, I would be able to question him, and not rely upon information from ignorant persons. I would not give an opinion from the evidence, as you state it, as to whether that was an epileptic seizure, to any patient of mine, upon any such statement as $I$ heard this morning.

Q. Do you remember the statement of his condition at night, before the homicide?

A. Yes, sir.

Q. Of his weeping at noon, and his insisting on it man living eight miles distant, staying with him?

A. That is more to the point.

Q. Assuming the accuracy of that account, what does it indicate?

A. Without any further information, it indicates a condition of mental disease, or aberration.

Q. You have heard of his beating of the wall, and driving away the imps?

A. That indicates the existence of hallucination.

Q. That is insanity?

A. Not necessarily; hallucination does not bacome evidence of insanity unless the person accepts the reality of the hallucination, and acts in accordance therewith. A man may have the perception of figures on the wall, but does not believe it; he is no more insane than you. He may take that spittoon to be a rat; that is an illusion,-and he recognizes the falsity of it at once; but if he believes firmly and truly that he sees figures on the wall, or the spittoon is a rat, he is out of his mind, and insane.

Q. In the afternoon of Sunday, and after the homicide, he was in a condition baating at somathing like these spectres, what was his condition?

A. He probably had a delusion.

Q. Assuming the truth of these statem ?nts, is it your opinion that he had a delusion, and was insane? 
A. Yes, sir; but these answers are given under the idea that the patient was not drunk, and had not taken opium, and was not suffering under mental disturbance. A man may tear his hair from mental disturbance, and not be insane.

Hammond, Dr. William A., recalled and examined by Mr. Peckham, testified on behalf of the people:

Q. Where do you reside?

A. In the city of New York.

Q. How long have you been a practicing physician ?

A. Since the year 1848 .

Q. Have you given any particular department of your profession a special study?

A. I have, ever since I began the practice, given disease of the mind and of the nervous system a particular study, especially during the last seven years.

Q. During that time you have had considerable experience in cases of epilepsy?

A. During the last seven years I have notes of over 360 cases of epilepsy which occurred in my practice. I have treated more cases than that, and before I had seen a great many cases.

Q. In regard to epilepsy, about what is the proportion of people who are affected with epilepsy, having their minds impaired to such a degree as to become insane?

A. I think Dr. Gray has placed the true proportion at ten per cent., but probably fifty per cent. develop mental deterioration, the mind weakened in some of its parts ; it would require a very careful examination to detect it. In the cases of Julius Cresar and Napoleon Bonaparte, and Mahomet, they had peculiar hallucinations. The existence of epilepsy is perfectly compatible with a high order of intellect in certain parts. I think I have seen cases where particular faculties of the mind have been really exalted by the occurrence of epilepsy.

Q. State what the disease is ?

A. It is an affection of the brain and spinal cord which is characterized by loss of consciousness and spasms.

Q. There must be loss of consciousness?

A. Yes, sir, in a fully developed case; there are abortive forms in which there is a partial loss of consciousness, but no subsequent recollection of what has taken place. In the very mildest form of petit mal there are spasms, though not perceptible to the ordinary observer. 
Q. What takes place during the moment is not remembered ?

A. The very mildest form consists in loss of consciousness with vertigo, and a little fixedness of the eye, that lasts perhaps only an instant, when the individual, without falling or even losing the thread of his conversation, regains consciousness. A person may be walking in the street and does not lose a step. There is another form, embraced under the designation of petit mal, in which there is the loss of consciousness with slight spasms. Then there is another form, which is called the grand mal, which is generally preceded by a pallor on the face, an inarticulate cry, after that the person generally loses consciousness and falls as if struck, usually forward, striking the head; with that there is a fixedness of the muscles. The large muscles of the neck contract and press upon the jugular vein and that produces the discoloration of the face, which is the next symptom so far as color is concerned. With that occurrence of purple color, the fixed muscles relax and the person goes into convulsions, there is a twitching of the face, the tongue is forced between the teeth and bitten, and the urine and frees are involuntarily passed; the bloody foam from the mouth is due to the biting of the tongue and the saliva. After that the patient usually passes into a condition of stupor. He may be aroused so as to give intelligible answers; after that he may return to his unconsciousness. There are cases in which there is no stupor, although he may complain of headache and usually does, and there is some confusion of mind. Then there is the fourth form, the abortive epilepsy, in which the phenomena are irregular, and in which there is not generally, a complete loss of consciousness. In that there is not so much convulsion as in the others. I have seen a person cross the room and take another chair, and coming back again having no recollection, but during that period answering questions with a certain degree of perspicacity.

Q. 'Take the case where maniacal demonstrations either precede, or take the place of, or immediately succeed an attack of epileptic convulsions,--state the condition in which the patient would be during that paroxysm?

A. During a paroxysm of what is called epileptic mania the condition, as $I$ have seen it, is one of forced excitement, intense maniacal excitement with the face very red, the eyes suffused, the countenance exhibiting excitement of mind and of body. During that time the patient may perpetrate acts of violence, and very often does.

Q. What would be the nature of these acts of violence as regards the fury? 
A. Generally without motive; a patient under those circumstances is as apt to attack his best friend or himself; they lose the recollection of what preceded, and lose all idea of any motive.

Q. They have no motive?

A. Apparently not, unless it is a false one.

Q. They have a sort of blind rage?

A. Yes, sir.

Q. A tendency to repeat blows?

A. They frequently do, or they may, under the influence of maniacal excitement from epilepsy, be governed by illusion which takes its place at the time.

H. When fury passes, have they any recollection of what has taken place?

A. No, sir.

Q. These attacks of epilepsy, do they not usually occur about the same length of time in the same person?

A. They very generally do at first, but there is a tendency in the attacks to become more frequent as the disease advances. Thus a patient may be taken with epilepsy, and have but one attack a year, and gradually they will recur more frequently. It may begin, however, with frequent attacks.

Q. While a person is in this furious state, is it not a conclusive symptom of the passing away of that paroxysm of fury, which may precede, or take the place of, or succeed the epileptic convulsion, that the person ceases to be violent, speaks to those about him, relates what has taken place, and is obedient to the control and command of those around him?

A. Yes, sir; the best evidence of the return of the reason is the conduct of the patient.

Q. The fact that the fury has passed away and he speaks of what has been done, is conclusive evidence that that state of mind has passed away?

A. It would be to my mind.

Q. Is it not in your opinion the fact that when the patient is calm or has ceased to be violent, obeys those about him, recollects the violence he has committed, and gives the particulars how it happened, and when and why he did it, and there is no delusion about it; are not these facts conclusive that the act was not performed in the paroxysm of fury, or in that state of mind in which such fury breaks out?

A. It is conclusive evidence that if it was performed during an epileptic paroxysm, he is no longer in that paroxysm. 
Q. Is it not evidence that the act itself was not performed in that paroxysm, the fact that he remembers it and speaks of it, and gives a motive for it, and there is no delusion or illusion about it ?

A. Yes, sir.

Q. Is not among the first symptoms of dementia, the loss of memory of recent transactions?

A. I presume it would ordinarily be called loss of memory, but it really consists in the loss of power of attention. A thing does not make the same effect upon the mind. It gives the appearance of the loss of memory.

Q. Another symptom is the loss of the passion of love or hate, and of other passions, the loss of fear?

A. Yes, sir; not nacassarily the loss of power of expressing emotion.

Q. Can you state the circumstances which might give rise to such facts as have been testified to in regard to the prisoner?

A. Some of them might arise from a partial awakening from sleep, from sleep drunkenness. A person may be waked up in the midst of a dream or nightmare, and does not disassociate things from the dream. That might be one of the causes of the condition of the prisoner in the night testified to in reference to him. Then, too, they might come from transient attacks of cerebral congestion. I recall the case of a very prominent gentleman of this State who went into the hotel at Poughkeepsie, and in consequence of swallowing his food too rapidly, was seized with an attack of mania which lasted for a half hour or more, during which he attempted to injure himself and those about him. I have no doubt that he had an attack of cerebral congestion : such attacks are quite common in my experience, with symptoms of mania.

Q. They pass away?

A. Yes, sir, without obvious result. I don't believe the mind, however, will remain in the same condition as before. They might come from embolism, a little clot of blood that enters the circulation and plugs up one of the arteries of the brain. They might come from a blow upon the head. $\Lambda$ fall may produce them for a time. They might come from being consequent upon epileptic paroxysms.

Q. Did you hear the question I propounded to I)r. Montgomery this morning?

A. Yes, sir. 
Q. Embracing in that question simply what took place down to the time of his being in jail, or two or three days after the occurrence-what in your judgment was the mental condition of the man on the morning of the homicide?

A. Upon that statement of facts I would say he was perfectly sane.

Q. In addition to that, add the fact that he was confined in jail for about five months; what would you state in regard to the condition of the man's mind at the time?

A. Could not materially modify my opinion. I should not think he was perfectly sane.

Q. What do you mean by that?

A. Simply that from the first statement of the facts given me by you, there is nothing that indicates the man's insanity. The mere fact of epilepsy would not indicate any mental deterioration to affect his acts. The fact of the phenomena you have mentioned since would lead me to infer that he was not in a condition of absolute mental perfection.

Q. That his mind might have been somewhat enfeebled?

A. Yes, sir.

Q. And still he would know what he was doing?

A. Yes, sir.

Q. In addition to the facts which were included in my question, assume that upon five or six occasions, extending over several years, the last of which was two or three years ago, the prisoner disturbed persons sleeping with him, stating that he had seen imps; assume forgetfulness of these things in the morning : that during the week preceding the homicide, the prisoner exhibited symptoms during which he attempted to draw a post from the ground, saying, "Don't you see how strong I am ?" Upon one occasion he stated that he had been pursued by five men and the devil, when there was no pursuit. On the day preceding the homicide he had a conversation with the uncle of his wife, in which he seemed natural and calm, and betrayed no peculiarity in his action, speech or expression. He had gone home about 11 o'clock at night with his wife and child, after having conversed rationally and quietly during the day and evening, and in that state had reached his house and gone into his room. What would these additional facts indicate, taken into consideration with the other facts as to his condition on Sunday morning?

A. They would give me no additional information, in regard to his mental condition at the time of the homicile. I should supvoc. XXIX-No. III.-D 
pose that he was subject to attacks of mental aberration resulting from epilepsy.

Q. And he would have no recollection of what occurred during these attacks after coming out from it?

A. No, sir.

Q. When was the first examination you made of him?

A. The first was day before yesterday, when I examined him in the jail.

Q. Describe fully the extent of that examination, and what took place between you and him?

A. I spent probably about half an hour with him. My attention was first directed to his face, and I think he exhibits evidence of being of a low order of intellect, and possessing a sluggish sort of mind. I base that upon the expression of his face and dimness of his eyes, and the absence of facial lines spoken of by Dr. Gray. I think his face is turgid, similar to his hands. I can't recall an instance when there was so great a turgidity of the hands as he has. I asked him a number of questions, to all of which he gave perfectly intelligent and rational answers, perfectly and conclusively connected with the question, except in regard to the homicide: in regard to that he expressed an utter want of knowledge. I asked him if he had had a child, and he said he had. I asked him its age, and he said a year. I asked its name, and he said Andrew. I asked the sex of the child, and he said he did not know. My impression about that was that he was deceiving me. I questioned him further about his habits. I asked him if he drank anything, and he said he occasionally drank a glass of beer. I asked him if he did not occasionally drink a glass of whisky; he said he might occasionally, but not to excess. I felt his pulse, and it was about one hundred and ten, running from one hundred and eight to one hundred and ten; it was rather feeble. I examined him with an instrument for determining the amount of sensibility he possessed, because, in my experience in cases of dementia, there is a lack of sensibility of the skin ; and $I$ endeavored to determine with an instrument whether he possessed the ordinary normal sensibility. I found he did. The instrument is what is known to mechanics as a beam compass. The sensibility of an individual is measured by the obscurity of his perception in reference to whether he is touched by the points. The person will not feel the two points if at a less distance apart than three-quarters of an inch. I found that he possessed the sensibility on the side opposite the defective ear, which I think is the right ear; upon the left 
side there is a slight want of sensibility. I detected that, more particularly, at my second examination.

I examined his eyes with the ophthalmoscope, for in cases of dementia, I should expect to find the circulation in the vessels in the eye, unnatural. I find the vessels perfectly natural, and the circulation natural. He said that the light hurt him very much, and he contrasted his eye to a certain extent, so that it was a long time before I could get a view of it; and every time I attempted to examine the eyes he closed them, until I spoke tolerably sharp, and I observed that there was not that excessive sensibility which his motions would lead me to expect. I examined him with reference to the shape of his head. At the second examination, I asked him first, if he had found out what sex his child was, and he said he had; that his brother said it was a boy; I asked him if he knew me, and he said he did; I asked him if he had seen me in the jail, and he said yes. I examined his ear, but could not make a satisfactory examination without an instrument. There is a little indication of moisture, which indicates a trouble about the ear; whether that extends to the inside of the skull, I could not tell; but I am inclined to think it does, from the fact that he had the trouble when young. I presume it did not injure his hearing. I found his pulse 108 to 110 . When I put questions to him, which allowed of any mirth being exhibited, he smiled in a natural way, and his appearance was altogether brighter when $I$ examined him, than it is in the court room, although $I$ think he is of a low order of intellect. I don't want to be understood that he carried on a conversation with me: he answered my questions intelligently and rationally, but he did not originate any conversation.

Q. He did not speak unless you spoke to him ?

A. No, sir; when I asked him the sex of his child, his face lighted up to a degree that surprised me. I should judge from his manner that he had been attaching considerable importance to the question.

Q. Taking all the facts which I have assumed in my questions to you, and adding to these facts the examination you have made of the prisoner; what, in your judgment, would all these facts, and the examination, lead you to think of his mental condition at the time of the commission of the homicide in November last?

A. They would not essentially modify the opinion I have already expressed.

Q. His condition was sane?

A. Yes, sir, from the state of facts you have given me. 
Q. Would not the fact that a man betrays, from the time of its birth, great anxiety about his child, in regard to its morals, after the commission of such an act, afford strong evidence that such person was not suffering from dementia?

A. Yes, sir, very strong.

Cross-Examined by Mr. Martindale.

Q. Assume that on the night of Saturday he was wild, appeared as though he had no fear, insisted upon a man staying with him all night, who lived out in the country and was temporarily there, and when responded to, that he could not do it, told him he could do it as well as not, and in a manner to inspire fear. Assume, also, that there was a condition of actual mania upon the preceding Thursday, he secking to escape from the pursuit of tive men and the devil, by getting around a waigon that night, followed by want of sleep. Assume an actual, convulsive, epileptic fit on Tuesday. Assume that the Monday night before he had manifested the appearance which has been described here by his father, whom he told to say the Lord's Prayer, quick, quick! Assume that on the afternoon of Sunday he was wild, answering that he had been in jail a thousand years, and saying, without apparent cause, "Go away, you have troubled me long enough." State to me your opinion as to whether the prisoner is sane or insane?

A. Assuming the truth of the facts which you have given me, I should be very certain to view the act with a good deal of suspicion, as to its being the act of a man in the full possession of his intellectual faculties. I should presume, without further inquiry, that the case was one of very grave doubts, and I am inclined to be in favor of the prisoner, and I should then be driven back to the act itself.

Q. Assume that all you know about the act, is first what you can get from the character of the act itself. That having retired, in early morning the prisoner is seen but partially dressed, and going out from the house, and that one single blow had been dealt upon the head of the woman, and he rushing then to kill himself. What would be your opinion as to the character of the act?

A. Setting aside the evidence in regard to his having waited five minutes, I should be inclined to think it was an act perpetrated under the influence of temporary insanity.

Q. All there would be to create a doalst, would be the estimate of the length of time he stood orer his wife? 
A. That would be the main element; the fact of his stopping long enough for reflection, would be incompatible with its being an act of insanity.

Q. You have referred to cases where a party is under delusion in regard to the wife's fidelity. Does the fact that it is a delusion operate on the insane mind in another way than the fact would operate if true?

A. It would act the same.

Q. If it were a fact, it would have the same effect?

A. It would have the same force.

Q. Assume that this young man had been religiously brought up, an industrious, hard working man, not addicted to intemperance or other vices. What effect does that have on the opinion you have expressed?

A. I don't know that it would essentially modify it; perhaps, upon fuller consideration, it might make it somewhat stronger.

Q. Your attention has been called to paroxysmal insanity?

A. Yes, sir.

Q. Were you a witness in the trial of McFarland for killing Richardson?

A. Yes, sir.

Q. And you gave evidence that he was insane ?

A. Yes, sir, and he was acquitted upon my evidence; but he had given evidence of insanity for weeks, and he is now in an asylum. There are a number of cases on record in which persons have been impelled to commit acts of viole nce, in which there has been no delusion, but in which the person has been irresistibly impelled to commit the act in question.

Q. When an epileptic has suffered from an attack, does the mental disturbance continue several days?

A. It does frequently.

Q. And during the time may he transact business without attracting the attention of experts to his condition?

A. Yes, sir.

Q. Are you aware of the fact, that the suspicion of insanity attaches for several days after the known attack?

A. In the French Courts an act of violence committed by an epileptic within three days after a well known convulsion, is sufficient to throw the onus of proof upon the prosecution.

Q. Assuming all these facts, what is your opinion as to whether he is sane or insane?

A. I have some facts in regard to him which you have not 
stated. I think I understood that he has had no epileptic paroxysm since in July; a period of fully six months has elapsed without a paroxysm. I think he is sane enough now to know the consequence of his acts.

Q. Do you mean he is now a sound man?

A. No, sir.

Q. Do you think he is suffering from cerebral disease?

A. Yes, sir.

Q. That is, disease of the brain ?

A. I think so.

Q. That tends to enfeeble him both physically and mentally?

A. Yes, sir, but from the fact of his having no paroxysms for six months, his mind ought to be in a better condition than it was six months ago, and I labor under the disadvantage of not seeing him before, or of examining him before it occurred. I don't know with any degree of certainty, whether his present siluggish intellect is natural or otherwise. I am inclined to think it natural, but give my opinion with some reservation.

Q. Are you able to state, assuming that during the time he has been in the cell he has had an idea of an attack by some person in the cell, and having violent headaches, and with these other concealed facts of his epileptic condition, what would you think of his having a seizure of petit mal?

A. It might have been, but I should not infer it from that state of facts. He may have the same symptoms from slight causes, from indigestible meals for instance.

Q. Assume that after the departure of his wife in October, he converses about the loss of his child, and that during the conversation his appearance changed, he turned red in the face and cried and laughed at the same time, and then proposed suddenly to pull up a post that all the folks in the house could not pull up, and then starting and going away?

A. I should think he had had an attack of petit mal.

Q. And that he was then in a fit of insanity ?

A. Of mental aberration.

Q. By that you mean insanity?

A. I mean insanity as scientifically considered; such an act is very similarly performed by a young lady now under my charge.

Q. You heard the description by Dr. Gray of a patient in the Asylum, a man who thought his wife was unfaithful to him, who conversed about his aocident, but who after loreaking his arm actually forgot it? 
A. That is a very striking and interesting case, it is almost unique. I think he must bave been unconscious most of the time. At the same time he thought the medicine administered to him was poison.

Q. Take the case mentioned by Dr. Cuok of the person now under his treatment, continuing for a number of days talking, and talking coherently while in this condition, and afterwards entirely forgetting everything.

A. The impression I got of that case was, that it was a case of insanity in which epilepsy had supervened, which is a very different thing from the case we are considering. I don't think that was a case of epilepsy with superinduced insanity.

Q. It is your opinion that epileptic insanity may be associated with insanity of a different character?

A. Yes, undoubtedly.

Q. You are familiar with Ray's Medical Jurisprudence ?

A. Yes, sir.

Q. In his treatise upon insanity, there is a statement that the attacks sometimes occur without warning but often preceded, \&c. ?

A. There are no cases in my experience so difficult of enquiry as epileptics.

Q. Are there the evidences here to your mind of the most powerful exciting causes?

A. There are powerful exciting causes, but the circumstances of the act as detailed, are not consistent, to my mind, with those of an epileptic, with all the antecedents of the prisoner and his subsequent conduct; his indisposition to escape, his voluntarily confessing the crime, are incompatible with such an act committed during an epileptic seizure, as well as the fact of the prisoner considering the matter for five minutes before committing the act.

Q. Suppose, in fact the party, as he rose and saw the ax-seeing the ax may have excited him ?

A. The sight of a murderous weapon may excite an insane person.

Q. Suppose a person attempts to resist the impulse and then yields and strikes?

A. That is rather a different condition of mind. In temporary insanity from cerebral disturbance, there is no disposition to resist.

Q. Are you acquainted with Dean's Medical Jurisprudence?

A. Yes, sir.

Q. Would not the starting of the idea, by the sight of the weapon, and the commission of the act, occupy an interval of time; 
may there not be an appreciable interval between the impression and the execution of the blow?

A. There might be some interval, of course.

Q. The duration of that interval is all the element in this case which would excite doubt in your mind?

A. The duration of the interval, the statement of the prisoner that he had waited five minutes, is the principal element; and the other statement that he was unable to live with her under the circumstances, is another element.

Q. And the statement that he was unable to resist the impulse, assume that instead of five minutes it was five seconds?

A. Then the main element would be taken away; but there would be still remaining the element of motive, and there would be still left the suspicion that it might be done in the heat of passion.

Q. The party whom he strikes is asleep, does that not materially affect the character of the act?

A. Yes, sir ; but then there is the statement of the prisoner that his temper got the better of him.

Q. Do you mean that in your judgment the infliction of that blow suddenly, on a sleeping woman, where there was no appreciable interval of time, connected with these preceding conditions of excitement, wildness the night before and actual convulsions during the week, do you mean to qualify your opinion that it was an insane act? What is your opinion?

A. In the recent questions which you have been putting to me I have understood that you are endeavoring to get my opinion as to the state of his mind at the time of the act. So far as the act is concerned it touches nothing. If $I$ come into a room and see a person drawing a pistol upon another, I don't know whether he is in the heat of passion, or intoxicated, or in a fit, or in a moment of insanity.

Q. If he had an epileptic convulsion during the week before, deluded with the idea that he had been pursued by five men and the devil; he was wild the night before, and he is an epileptic; what then?

A. Those are all circumstances which I have taken into consideration; they are entitled to weight; they are an issue requiring a medical witness to give an opinion with great care and caution, and they alone, would govern him in my opinion. But I have other fac of his having quarrelled with his wife in the night, or that he said so. 
Q. Assume the fact that there is no evidence that he quarrelled with her, but that he solicited her not to go with other men, and she refused. Assume that they had no words before he got up; that is my understanding of the evidence; suppose when he got up there was no provocation and no words, and he loved her, and struck her because he was unable to resist ?

A. Assuming the truth of that, he was insane.

\section{Re-Examined by Mr. Peckham.}

Q. Assume that he had these words the night before, after he got back, or in the morning, and that he had great anxiety in regard to his child, and also that he said he loved her, but would rather see her dead than continuing to live in that way, and he had rather see his child dead than brought up in a house of prostitution, and he then got the ax and deliberately struck the blow ?

A. It was a sane act. Deliberation takes away the idea of an insane act.

Q. Instead of tha wildness spoken of, take the case that the man at eleven o'clock at night on Saturday, betrays it to no observer; that he is in the company of a man who has been with him most of the day, and he goes home, having had a calm, connected, coherent conversation, then what was his condition?

A. Those are additional facts that tend to show his sanity.

Q. Suppose he asks a man to stay with him in an excited way, but when the man says he can not, he says yes, he can; but on his repeating it allows him to go, and subsequent to this time he has, this long, calm conversation with his wife and her mother, and her uncle, and leaves the house at night in a perfectly calm manner?

A. These facts would tend to strengthen my opinion.

Q. Of sanity?

A. Yes, sir.

Q. Is not the fact of delusion one of the principal, if not the principal evidence of insanity?

A. It is one of the evidences.

Q. And, although a party might act when the delusion is present and perform a furious act, would it be the same kind of an act, so far as the mental capacity was concerned, as if there was a motive?

A. It would be.

Q. Suppose a man had known two years that his wife was unfaithful, added to these other facts?

A. That would not increase my idea of his sanity. If he 
endorsed quietly such a state of affairs it would show a pretty low order of intellect.

Q. And not a keen appreciation of his own honor?

A. No, sir.

Q. But it would be an entirely different case to that where the knowledge was just sprung upon him?

A. Yes, sir.

Q. In regard to the fit of Friday, have you ever known a case of an epileptic fit or seizure when, during the continuation of it, the party will be spoken to and will answer and then relapse into the same condition, and being spoken to again will answer and relapse again?

A. Never.

Q. Is not such a thing incompatible with the idea of an epileptic seizure?

A. I think so, entirely.

Q. If an assumed fit should be described to you as epileptic in its character, where there was an assumed frothing at the mouth, and it should be also given to you as a fact that during that very time he spoke when spoken to, and answered questions put to him, would it not be conclusive evidence that it was not epilepsy?

A. Yes, sir, with the frothing at the mouth, but there are conditions of epilepsy which are abortive.

Q. Supposing he remembers the fact of a woman calling for him to take her trunks, but forgets where he was to go?

A. I should say very certain that it was not an epileptic attack.

Q. In regard to the case spoken of by Dr. Gray, there was delusion, and during the time of supposed unconsciousness he had the delusion in regard to his medicine, and the whole idea of his unchastity was entirely a delusion?

A. I so understand it.

Q. After he came out of these attacks he failed to acknowledge that it was a delusion?

A. Yes, sir.

Cross-Examined by Mr. Martindale :

Q. What is your opinion of a person who appreciates the value of chaste character, an industrious man marrying and hẹaring his wife is a prostitute, which gives him great distress, and yet he endures her and loves her. What is your opinion as to the effect of that fact as bearing upon his mental condition?

A. The two things I think are somewhat contradictory. 
Q. Assume the fact to be that this person shows those irregularities and eccentricities?

A. They are evidence of a weak mind.

Q. They are evidence of a very affectionate temperament?

A. Yes, sir, but of weak mental power.

Q. When McFarland shot Richardson, the passion was excited by the idea that Richardson had debauched his wife?

A. Yes, sir.

Q. In that case in your opinion, the idea of infidelity had absolutely excited an insane homicidal frenzy?

A. Undoubtedly; I do not know of any circumstance in the whole range of society, which is more calculated to excite it than that thing.

Q. Does this man's face furnish any evidence of disease?

A. It does.

Q. What kind of disease ?

A. I am very clear in regard to the existence of disease of the brain-cerebral disease.

(Question by Mr. Peckham:)

Q. That is entirely and totally different from insanity ?

A. Yes, sir ; although insanity can't exist without disease of he brain.

(Mr. Martindale, resuming.)

Q. Where cerebral disease is progressing as in this case, and epilepsy is associated with it as in this case, and where the person has attacks of insanity as you have described them, and there has been an attack of epilepsy during the week preceding the actWhat would be the medical presumption as to the insanity at the time of the commission of the act?

A. A priori, at once, that the person was insane, and it would require inquiry to dissipate that presumption.

The reader must have noticed the striking conflict between the answers given by Dr. Hammond to the prisoner's counsel and to the District Attorney respectively. I will examine the medico-legal points in the case of David Montgomery as categorically presented by Dr. Hammond himself, in a review published in the Journal of Psychological Medicine for January, 1872. 
I will base my opinions on the facts, as directly testified to on the trial. Dr. Hammond, in the article just cited, clearly overlooks evidence of great weight going to prove that Montgomery was an irresponsible agent when he struck his wife, and that he labored at the time under epileptic insanity. The facts as presented by Dr. Hammond in his article differ in many essential points from the testimony I have already noticed. Dr. Hammond says: "The medical experts who supported the theory of the prisoner's insanity were Dr. Cook, of the Asylum at Canandaigua, and Dr. Gray of the Utica Asylum; those who thought differently were Drs. Moore and Montgomery of Rochester, and myself." The records of the trial show, nevertheless, that Dr. Edward M. Moore, was sworn for the defendant, and testified as his conviction, that Montgomery was insane; that he exhibited an insane susceptibility and maniacal excitement, due to the recurrence of epilepsy. [Dr. Hammond, however, omits to mention Dr. Whitbeck who did agree with him.] Dr. Hammond's opinions rest upon particulars, mainly derived from the prisoner, completely ignoring the important events in evidence portraying the mental state of Montgomery, and his diurnal fits throughout the week, as also on the very day before the homicide. How much at variance the history given by Dr. Hammond in the Psychological Journal is, with that which has been here faithfully abstracted from the records of the trial may be judged from the following quotation:

"The prisoner Montgomery is twenty years of age, has followed the occupation of a carter, and has never been suspected of mental derangement, dementia, or epilepsy, by those who knew him, outside of his own family. [During the trial the following witnesses testified, most positively and directly, as to their sceing Montgomery acting crazy, while in one or more obvious epileptic fits: to wit, Philip Bachs, Susan Papino, Christine Cuthbert, Isabella 
Macbeth, Rosetta Kennison, Mary Jane Fisher, former nurse at Canandaigua Lunatic Asylum, Catharine Donovan, Phebe B. Westcot and Robert $Y$. and Catharine Metcalf; ten witnesses outside of the members of Montgomery's own family.] Several members of the family, however, testified, in the previous proceedings relative to his sanity, that he had been subject to epilepsy since infancy, but the Commissioners could only satisfy themselves that he had three attacks up to the time of the homicide; therefore, it may easily be assumed that, notwithstanding the possible existence of epilepsy, his mind has not, in consequence of such disease, undergone marked deterioration. [In addition to the three attacks of grand mal, the Commissioners declare to have found evidence of numerous scizures of petit mal, and that at these times Montsomery exhibited maniacal excitement with tendency to violence, $-2 \mathrm{~d}$ conclusion of report.]"

"At the age of about eighteen he married, but had lived upon bad terms with his wife, who had been a prostitute, and who insisted upon returning to her former occupation. A week before the homicide she left him, taking with her their child, eight months old. [It is in evidence that Montgomery took the child to his father's house and kept it, until he went to see his wife with White, on Saturday noon, when the young brother-in-law brought the baby to its mother.] On the evening of the day, Saturday, before the homicide, Montgomery went to her mother's, where she was stopping, and parsuaded her to return home with him. They arrived at their own home about twelve o'clock at night, and she was killed the next morning, between the hours of six and eight. Many of these particulars, as well as the subsequent ones, are derived from the statements of the prisoner. [This certainly accounts for their want of correspondence with the evidence bearing on the above points.] From these statements it appears, that they awoke carly in the morning, and began to talk of their difficulties. He told her, that, if she would remain at home and stop going with other men, he would forgive her. She replied that she would not, that she was a prostitute when he married her, and he knew it, and that she had always been one, and always would be one. IIe replied that he had made up his mind that, if she would not live with him, she would not live with any one else. He then got out of bed, partially dressed himself, and went to his father's house, a few rods distant, and took from the back yard an ax, with which he returned to his own residence. On entering the room where his wife was, he found her asleep. Ie stood by the stove a few minutes, delib- 
erating whether he should kill her or not. Finally he determined to do so, and then struck her on the head, just above the left temple, inflicting a mortal wound, of which she died."

"He then left the house, and, meeting a younger brother in the street, told him what he had done, and then taking a razor from his pocket attempted to cut his throat. In this effort he was prevented by his father and brother, and was by them persuaded to give himself up to the police. On his way to the jail he stated to the officer,that he had at first thought of going to Canada after killing his wife, but, concluding that he would be caught, he had determined to give himself up. In these particulars there is no one fact indicating insanity, dementia, or epilepsy, besides the fact of voluntary confession and surrender. This, unaccompanied by other evidences of mental aberration, is of little importance, and is materially lessened in its force by the opinion of the prisoner, as expressed to the policeman, that he thought he would be caught if he attempted to escape. As regards temporary insanity from morbid impulse, there is no evidence to show that Montgomery had exhibited any indications of mental derangement during the few days preceding the homicide." Quarterly Journal of Psychological Medicine, January, 1872 ; page 66, et seq.

So far as the mental state of David Montgomery is concerned, it would be entirely out of place to judge of it but by the real facts in evidence. The history just quoted contains a great deal of hypothetical matter, it being reproduced here only to make manifest the inaccurate premises to the conclusions drawn by Dr. Ham. mond; and any theory built upon such foundations will hardly be admissible to elucidate the case of David Montgomery. There are, however, scientific assumptions which have been made during the trial and reaffirmed, most of them, in the article under consideration, which call for more than a passing remark.

"It by no means follows that an individual suffering from epilepsy is not as fully responsible for his actions as healthy persons." This point is asserted by Dr. Hammond in a manner too absolute to be safely accepted as that of a medico-legal guide. No alienist ever pretended 
that, from the mere fact of having been subject to epilepsy or insanity at some previous time, an individual becomes thereby irresponsible for his civil or criminal actions; but when, as in the case here examined, the commission of the act and the epileptic seizure succeed each other, when a close relation exists between the two, or again, when the act is perpetrated during that state not yet clearly appreciated of epileptic insanity, the responsibility of the individual becomes questionable and is so acknowledged by such high authorities as Delasiauve, Falret, Trousseau, Legrand du Saule, Castelnau, Baillarger, and many others.

The weight of Reynolds' authority is brought to confirm the opinion that, "epilepsy even when fully pronounced does not necessarily involve mental change. In 38 per cent. of Reynolds' cases the mind was unaffected in any way. He further declares that while considerable intellectual impairment exists in some cases, it is the exception and not the rule; and also, that ulterior mental changes are rare." It is, indeed, strange that the glaring contradiction into which Reynolds falls on proclaiming the above results should not have struck Dr. Hammond; for, most assuredly, if 62 per cent. of the epileptics under Reynolds' care exhibited mental change, the intellectual impairment can not be a rare exception with epilepsy. On the next page to the one where Reynolds lays down these conclusions and gives his reason for doubting the existence of any necessary "consequences" of epilepsy, he writes, contradicting himself, under the heading of "Complications especially 'nervous' in their character"-_Besides the failure of the intellect, which has been already shown to be frequently associated with epilepsy, there are special conditions of disturbance to be met with in some individuals; these conditions occurring in more or less definite 
relation to the attacks. Thus, mania not unfrequently complicates the affection of the epileptic, and epileptic mania has a characteristic of its own. In the sixty-nine cases which have been analyzed in this treatise, some attack or attacks of mania occurred in seven individuals, or in 10 per cent., viz: four males and three females." ("On Epilepsy." London: 1861. p. 206.) The insufficiency of sixty-nine cases upon which to rest these conclusions is too apparent. The number is too small to furnish any precise data, and, consequently, we see Reynolds arriving at such conclusions as the following, introduced here simply to confirm our assertions: "The duration of epilepsy exerts a slight and doubtful influence upon the mental, motor, or general health of the patient. Epilepsia mitior is not essential to, and does not especially produce mental failure," although in another place Reynolds declares that, "the attacks of epilepsia mitior are relatively more common among those whose mental condition is impaired than among those who exhibit no intellectual failure," which naturally indicates that there must be some important relation between epilepsia mitior and mental failure. Then, again, "the mental condition of epileptics does not depend upon the age at which the disease commenced, whereas early commencement of epilepsy, or commencemenc before puberty, is of favorable omen in the prognosis of an individual's intellectual chance." "Epilepsia mitior can be considered neither the initial stage, nor the after consequence of the severer forms." Finally, "neither one of the following elements-kind of attack, frequency of either form, rate of frequency, nor duration in years-is either by itself, or in combination with the other elements mentioned, sufficient to determine the mental condition of the patient."

If $I$ have been particular in presenting the foregoing 
quotations it is because I also recognize the work of Reynolds as one of the best on Epilepsy. But, I have statistics of 532 cases which disprove the above conclusions. That the development of epilepsy in infancy, or before puberty, is observed among individuals most of whom are tainted with a hereditary predisposition to the disease, and that it also usually impairs the intellectual faculties, is a fact too well known by those in charge of epileptics; wherefore, instead of considering it as a favorable omen, I look upon it as one of the most adverse circumstances in the etiology of epilepsy. The efficient part that epilepsia mitior takes in the production of general spasms is too self-evident and indispensable to be regarded as a mere coincident event. Nor could I say, after a large experience with epilepsy, that the kind of attacks, frequency of either form, rate of frequency, or duration in years, are neither separately, or in combination, sufficient to determine the mental condition of the patient. The com. mencement of epilepsy in infancy, the frequency of its attacks, the combination of the epilepsia mitior and gravior, and the great recurrence of the former, have been the most potent factors to induce mental deterioration in the cases under my observation, and, in these respects, my experience fully agrees with that of Esquirol, Delasiauve, Falret, Trousseau, Baillarger, Morel, and others. Boileau de Castelnau, in his standard work "On the Relations of Epilepsy to Mental Alienation," says: "When epilepsy has lasted a long time one must expect to see it ending in enfeeblement of the intelligence and of mobility. The younger the individual at the commencement of epilepsy the more mental alienation is to be dreaded." It is not, therefore, by accepting any of the singular conclusions of Reynolds in regard to the mental state of epileptics Vor. XXIX.-No. III.-E 
that we may be able to understand the true nature of the mental condition of Montgomery when he murdered his wife, or trace the crime to its true origin, his epileptic disease, displayed by numerous attacks of petit mal, with less frequent of haut mal, and the condition of dementia, or rather of epileptic insanity, noticed by the four Commissioners, and which was still persisting on the 24th of last August, when the writer visited Montgomery, and made a careful examination of him.

Dr. Hammond testified that: "Not many cases of epilepsy are accompanied with insanity or olvious mental deterioration. According to his experience fifty per cent. [are not these a great many ?] develop mental deterioration, their mind being weakened in some of its parts." Few will hesitate to agree with me in the great difficulty of drawing the line ketween insanity and mental deterioration or a mind weakened in some of its parts. As no recognized standard exists on the subject, nor can any line of demarcation be fixed where responssibility ceases, and irresponsibility, by reason of a mind deteriorated or "weakened in some of its parts," begins, it is, indeed, unsafe to leave such a question before a jury for their deliberation. Mental failure has been evident in 374 of the 532 epileptics whose history I have analyzed, or in 70.3 per cent. Of this latter number 267 exhibited attacks of mania, lasting from a few minutes to several days or weeks. One hundred and thirtythree, or a little over one-fourth of the whole number, were subject to periodical fits of cerebral or larvated epilepsy, alternating with, or supplanting the convulsive attacks. In regard to mental failure I may further state, that in all the cases where epilepsy has been attended with paralysis, and the fits have kept a progressive course, a more or less manifest impairment of the intellectual faculties, an ohvious state of dementia, 
has always been present. I have noticed the fact particularly in 248 cases, but 123 of them are exclusive of the 532 above referred to, because epileptiform convulsions and paralysis were displayed from the outbreak of the disease, and I do not, therefore, consider them as instances of genuine epilepsy. My observation concurs in this respect with that of Sir Henry Holland, (Medical Opinions upon the Mental Competency of Mr. Parish. New York: 1857. p. 570,) who says: "Having in an active practice of forty years, seen and noted very many cases, in which successive paralytic and epileptic attacks were conjoined, I do not recollect a single instance among these, in which the intellect was not more or less impaired, and very seriously impaired, when the epileptic fits were as frequently repeated as in the present case." The only object I have had in view, in bringing forward these statistics, is to make it manifest-that mental changes are in nowise exceptional or rare, but most frequent phenomena in the history of epilepsy, notwithstanding the statements to the con: trary made in Montgomery's trial by Dr. Hanmond.

I must make one more remark before disposing of the subject, namely, that the proportion of epileptics whose mind becomes impaired to the degree of insanity in consequence of their disease, is a question wholly immaterial and of no medico-legal bearing upon the question whether Montgomery, afflicted with epilepsy, was or was not accountable for the murder of his wife. It has not been held by the defence, nor by the skilled medical experts who testified to the insanity of Montgomery, that epilepsy leads to insanity in every instance, and that therefore Montgomery was insane. What the physicians verified, upon personal examination, is, that Montgomery, in addition to the other physical manifestations peculiar to epilepsy, displayed signs of dementia, pre- 
ceded by undoubted fits of haut mal and numerous seizures of petit mal, seizures of the worst form, dating since infancy. Consequently, all that was required on the part of the people was to disprove this point and the several facts in evidence, occurring successively during the week previous to and for hours after the homicide, which bear on themselves an unmistakable stamp of epileptic insanity. It is not because Montgomery ever had epileptic fits, but because he labored under epileptic insanity, at the time of the homicide, which was preceded by several paroxysms recurring during the week previous, that he should be declared unaccountable for it. The reality of Montgomery's insanity could not be affected in any manner whatever, whether one or seventy actually become insane out of a hundred epileptics; for, let me repeat it, the sole point at issue was that Montgomery was in such a state of epileptic insanity on the morning he struck his wife.

According to Dr. Hammond, little importanse should be attached to the views of Asylum physicians on the subject of responsibility of epileptics, because the epilep. tics in lunatic asylums are at the same time insane. This opinion is proclaimed as in keeping with those put forward by Falret in his valuable essay "On the Mental State of Epileptics," wherefrom a passage is quoted in which the eminent French alienist arrives at the follow. ing conclusion:

"The question therefore, of the responsibility or irresponsibility of epileptics can not be defined in an absolute manner, since we must consider certain epileptics as guilty of the acts imputed to them; at certain periods of the disease, the appreciation of this responsibility becomes extremely delicate in each particular case. Thus the only practical manner of putting medico-legal questions relative to epilepsy and mental alienation is 
that which has been hallowed by custom. Was the individual of sane or insane mind when he committed the act for which he was arraigned before the bar of justice? If he was insane, he ought to be considered irresponsible: if not, he ought to be condemned as guilty."

Having carefully studied Falret's most excellent work, I fail to discover in it any views coinciding with the extreme opinions so unreservedly put forward by Dr. Hammond. In regard to the conclusion just quoted, it is indeed in accordance with the soundest views held by every alienist who has paid special attention to the sub. ject of epileptic insanity; and obviously of no appli. cation to sustain the grounds against its admission in Montgomery's case. There are yet, other statements following the above passage, which manifest most clearly and concisely that Falret has endeavored to propound a very different doctrine from that ascribed to him by Dr. Hammond. A few lines below the point where Dr. Hammond stops, Falret says: "Instead of endeavoring to measure the morbid impulse in each in. dividual, and the amount of resistance which his will could oppose to it, (both of which it is impossible to estimate with exactness,) certain authors have sought to discover more practicable means whereby to decide upon the normal freedom of epileptics at the time they perpetrated the act for which they are charged. Some of them have granted that the same patient may at the same time be declared responsible for certain acts and irresponsible for certain others, according as the acts were, or were not, in direct relation with the ruling abnormal idea or impulse. It has been sought to apply, not only to epilepsy but to different kinds of partial insanity, this doctrine which appears to us altogether inadmissible. We can not comprehend this division 
of the human individuality into two parts, of which one would be led irresistibly by a delirious idea or a morbid desire, while the other would retain its self-control and would be considered responsible for its act."

* * "In doubtful cases, that is to say, when the civil actions have not been performed during the manifest paroxysms of mental disease, (as those of mental grand, or petit mal,) nor yet during a continued state of insanity, such as exists in inveterate epileptics, they should ordinarily be considered valid. We can not, in. deed, according to our idea deprive a whole class of persons, whose disease has already entailed upon them so many misfortunes, of the exercise of their civil rights, and this, when experience has shown, that, notwithstanding changes of character and temporary weakness of mind, these persons may enjoy in the interparoxysmal periods long intervals of reason. We think, therefore, that generally.speaking, in a doubtful case, one ought to incline the balance in favor of validity of action, whenever the point is discussed in civil cases, whereas it should be inclined in favor of irresponsibility in criminal cases."

It is curious but true that the last strange contradiction, and the preceding clear statements, prove very plainly that Falret extends the irresponsibility of epileptics in criminal cases far beyond the limits stated by Dr. Hammond, whose views could not be consequently admitted as fully concurring with those advanced by Falret. Evidently it has not been Falret's intention to lessen the capacity of asylum physicians to pass correct opinions on the subject of epilepsy. Proofs abound throughout the above quoted work and his other writings, to show that Falret believes it is only by close watching of epileptics in a hospital, and not in society where they can conceal their disease, that 
every shade or feature of epileptic insanity can be appreciated. The standard work of Falret on the mental state of epileptics, the result of his long experience as Physician to the First Section of Lunatics at the Salpetriere Hospital of Paris, is the most eloquent proof that asylum physicians have opportunities more likely to render them quaified to judge of the phenomena of epileptic insanity than others.

Dr. Hammond says-that insanity with epilepsy is a very different thing from the insanity which results from epilepsy; and, during the trial, declared that a case presented by Dr. Cook, where a patient, in a condition of epileptic mania, remembered what had taken place while he was in fury, was an example of insanity in which epilepsy had supervened, and not a case of epilepsy with superinduced insanity. Another similar case, described by Dr. Gray, and to which I will allude hereafter, was considered by Dr. Hammond as almost unique. Let us see if there is really any difference between insanity with epilepsy, and insanity from epilepsy; or, to put it more correctly, if the two conditions exist and differ from each other, and whether their difference has any medico-legal value. Boileau de Castelnau, in his model work "On the Relations of Epilepsy to Mental Alienation," says: "Observation shows that epilepsy leads to insanity, whereas the latter rarely superinduces epilepsy." In my long experience with epileptics I have not had occasion to record one case where insanity superinduced the epileptic disease. I have carefully inquired into the subject in 532 epileptics, whose history I have noted, and in 742 lunatics, who, up to this date, (September,) have been admitted into the New York City Asylum for the Insane, since its opening, December 13th, 1871. I may state, on such personal observation, that in every 
instance, paroxysms of petit mal, or grand mal, or nocturnal attacks preceded epileptic insanity, whereas I have come across no case in which insanity has in. duced epilepsy. Epileptiform convulsions, however, have occurred, not infrequently, in the last stages of dementia, in cases of melancholia with stupor, and in general paresis, but always in the advanced stages of the disease. In all but the last cases alluded to, the autopsies have shown, ordinarily, degeneracy, or plugging of the cerebral arteries: epileptiform convulsions then recur in frequent succession, not seldom leaving behind a choreaic movement of the head or of the face along with coma, in the interparoxysmal periods, and lasting for twenty-four or forty hours before death. I have not seen any patient recover from this condition; and I may remark besides, that epileptic seizures have been particularly noticed by J. T. Sabben among the symptoms indicative of atheroma of the blood vessels at the base of the brain. (Journal of Mental Science, April, 1870; p. 53.)

I am informed by Dr. John P. Gray, of the Utica Asylum, whose long experience and learning place him among the foremost of American alienists, that from the histories of some eight thousand patients received and treated at the State Asyluin at Utica, during the twentytwo years of his connection with that Institution, he has no recollection of a single instance of true epilepsy occurring in an insane patient; whereas in all the insane epileptics, admitted during that period, it had been ascertained that the epilepsy had preceded the insanity. He has observed, however, that maniacal or melancholic attacks not infrequently took the place of the epileptic seizures, for a more or less prolonged period, and had been sometimes mistaken in their true nature, where sufficient inquiry had not been made into the antecedent 
history of the individual. In these remarks, Dr. Gray excluded the common occurrence of epileptiform convulsion in general paresis, apoplexy, or cases of senile dementia. We may, therefore, safely acknowledge that epilepsy from insanity is an extremely rare if not a hy. pothetical state, not confirmed by any positive experience. There is, finally, as Falret establishes so truthfully, only one form of epileptic insanity in which the delirium and the convulsion may exist separately or simultaneously, or alternate with, or follow each other at short intervals, but having essentially the same pathological significance.

I will now allude briefly to the cases of Winnemore, Fyler, John Reynolds, and Chambers, asserted by Dr. Hammond, as instances in which epilepsy was improperly, used as a defence.

The facts in Winnemore's case are too familiar to the readers of the Journal of Insanity, to need further arguments than those so forcibly presented by Dr. I. Ray, who closes the review of the trial, by saying: "Left as it is, it (the case) gives the physician scope for abund. ant speculation, but no certain conclusion, while to the lawyer its results must seem more like a triumph of ignorance and passion, than of professional skill overcoming every desire and obstacle, and arriving at last to a sure and satisfactory end." That a mistake of judicial authority took place in Winnemore's case is too obvious a fact, whereas Dr. Ray declared Winnemore insane, and it is, therefore, unnecessary to dwell here upon this case unless it be to refer to the argument so ably presented on the subject, by such a high authority as Dr. Ray. (Amer. Jour. of Insanity, Oct., 1867.)

As far as the case of Fyler is concerned, he was an epileptic years before the alleged homicide. During the progress of the trial, in the Court Room at Syracuse, 
Dr. Gray recognized him as being in an epileptic seizure, and notified the Court, and the proceedings were thereupon temporarily adjourned. The evidence in the case did not bring out his condition antecedent to the crime with which he was charged as to whether he had had any epileptic attacks about that time. He was, however, convicted, but sentence was deferred, and immediately a medical commission was appointed to inquire as to the soundness of his mind. An examination before Judge Woolworth resulted in his being declared insane, and sent to the Asylum at Utica. He had nocturnal fits while at the Asylum after admission, and he was stupid and indifferent to his family. When visited by Judge Allen, who had tried him, and District Attorney Andrews,- - both now of the Court of Appeals, Fyler did not recognize either, and did not speak of their visit subsequently. He always denied that he committed the homicide, and maintained that it was the act of two persons who came into the house during the night. Fyler, on the night of the murder, had run to his neighbors, in his shirt, without pantaloons, coat, or shoes,-a cold night.with snow on the ground, and gave the alarm that two men were in the house. The persons accompanying him back found Fyler's wife dead,-shot and her throat cut, several doors opened in the house, and the drawers of a bureau out, with their contents scattered about. While at the Asylum, Fyler had a severe attack of remittent fever, after recovery from which his general health improved, and, afterwards, up to the time of his discharge in 1863, no epileptic attacks were known to have occurred in his case. In June, of 1863, the District Attorney of Onondaga County sued out a writ of habeas corpus under which Fyler was brought before Judge Allen, in the Court of Oyer and Terminer, held at Syracuse. Dr. Gray testified that Fyler was so 
far recovered from his insanity as to be able to take care of himself. The Court and counsel for the people, on investigation of the case, were of the opinion that sentence not having been passed upon Fyler at the time he was convicted of his crime, he was amenable only to the laws standing on the statute book at the time of his trial, and those laws having in the meantime been repealed by the Legislature, there was no statute under which he could be held or punished. Such being the decision of the Court of Appeals in Mrs. Hartung's case, the Court therefore discharged Fyler from further custody, his case being most remarkable, not only from the fact that it is the first in our criminal records where epilepsy has been interposed as a defence, but also from the unusual circumstance already detailed.

I have reviewed, in another place, the medico-legal tests of John Reynolds' criminality, as they appear in the certified minutes of the testimony taken by the Court stenographer during Reynolds' trial. I may declare that, as in Winnemore's case, nothing has disproved that punishment was too hastily inflicted upon Reynolds, against the dictates of law and justice, to gratify public clamor, whilst the medical testimony admitted did not truthfully represent, in a strict medico-legal or scientific sense, the important points it was intended to elucidate. I was informed by Mr. A. T. Spencer, in whose store, No. 80 East Fourteenth street, New York, Reynolds was employed, not only that he had a severe fall down two flights of stairs, during an epileptic fit, in the winter of 1868-69, but furthermore, that the very day Reynolds murdered Townsend, he was wandering about Williamsburgh, and in the afternoon entered a house in a bewildered state, seized a pitcher of water standing on the parlor table, dashed the water against the wall, and had to be ejected forcibly from the house. 
Of this occurrence Reynolds, of course, never spoke when called upon to give account of what he did during the hours before the homicide. Finally, it is a matter of record that Dr. R. Vance declared Reynolds a free agent, and that upon this and Dr. Hammond's testimony he was convicted and executed. Dr. Vance, when cross-examined by the Hon. Samuel B. Garvin, District Attorney, to whom he had a few days previously affirmed the above belief, gave in McFarland's trial, without any reservation, the following answer, transcribed verbatim from the minutes of the testimony taken by the stenographer of the Court, April 26th, 1870:

Question by District Attorney.-Describe a case in which insanity may exist without delusion?

Answer by Dr. Vance. "Take the case of Reynolds. There was no delusion there; the man acted as a mere machine having no consciousness of his act, and when he comes to himself he has no recollection of what he may have done." Let me repeat here, that the example needs no comment and could not be more striking, although this unhesitating and spontaneous acknowledgement on the part of Dr. Vance comes too late to benefit the unfortunate Reynolds, but not too late to evince that in spite of public clamor and prejudices, truth prevails in the end, and that the question of epileptic insanity in Reynolds' case offers a very different aspect from that represented by Dr. Hammond.

Concerning the case of Chambers, I will simply remark, that notwithstanding the excessive public feeling against the prisoner, and the earnestness of the prosecution, it was impossible to produce one single witness -excepting Dr. Vance-who would not testify in an unequivocal manner as to Chambers' unsoundness of mind or delusions, and his frequent unprovoked violence, or dangerous conduct, before the homicide. The testi- 
mony was of such an overwhelming character that the prosecution abandoned the case. One of the witnesses, Peter Hopkins, testified to having seen Chambers "perfectly deranged, his countenance worked with strong convulsive spasms, and he was turning around quite unconscious." From the facts in evidence, and the account Chambers gave me of the symptoms and feelings he experienced during his nocturnal attacks, in addition to his sudden unprovoked outbursts of violence, I came to the belief that Chambers was subject to epileptic in. sanity and so declared, urging most strenuously to the Court that he should be committed to a Lunatic Asy. lum, if found not guilty. The jury, without leaving their seats returned their verdict of "not guilty on the ground of insanity, and recommended him to be sent to a Lunatic Asylum." The court thereupon said: "We are perfectly satisfied that this man was insane, and that this insanity continues, according to the med. ical testimony, and our order is that he be confined in a Lunatic Asylum."

How significant the points that Dr. Hammond might have elucidated had he not had the misfortune to be prevented from getting to the court, and how much his evidence might have pressed home the conviction of the prisoner, setting aside the weighty proofs that convinced the court and jury of Chamber's' irresponsibility, it is not in my power to estimate.* I find nevertheless, no

* I I was requested by the District Attorney to examine the prisoner, I did so, and found no evidence of epilepsy beyond the statements of Chambers himself. On his trial another physician testified to the presence of epilepsy. Through a misadventure, I did not get to the Court to testify, and the prisoner was acquitted and sent to the Lunatic Asylum at Utica. He presents no signs as I have been informed by Dr. Gray, of having any form of mental alienation or epilepsy." Quarterly Journal of Psychological Medicine, January, 1872. W. A. Hammond. 
[January,

reason why so perplexing and so undecided a case, should be so readily disposed of and cited as one of simulated insanity. I am authorized by Dr. Gray to state that he has made no communication whatever in regard to Chambers, or touching his condition when he committed the homicide. I may add that, when Chambers was admitted to the State Asylum, he displayed not only a pearly appearance of the eye, puffy lips, and dull expression, but also the most intense lividity of the hands and feet, and this I notice, as consistent with the views of those who lay so much stress on objective signs as proofs of insanity. I visited in August the Asylum for Insane Criminals at Auburn and saw Chambers there. He exhibited a strikingly demented look, which has been particularly noticed by Dr. J. W. Wilkie, Superintendent of the Asylum, who informed me, that since Chambers' admission he has conducted himself very gentlemanly, although at times subject to nervous attacks, when he becomes excitable.

The opinion I expressed during Chambers' trial was mainly based on the testimony presented. I saw Chambers only once, the day before his trial, and could not have pretended to judge of his insanity, or mental state, on a single examination. I may be mistaken in having considered Chambers' case one of epileptic insanity, but I confess, that nothing has so far transpired to make me ehange my belief. The competent and leading alienists, who have had Chambers under observation, acknowledge that he is a dangerous man, but have not made public their opinion on his case. Leaving out of sight the real meaning of the expression "attacks" of nervousness, occasionally exhibited by Chambers now, there are one or two things at all events, which should not be overlooked; namely, the influence of incarceration and inforced abstinence from 
liquor, to which Chambers had been addicted, and his quiet life in the asylum, all which should be taken into consideration, if we are to suppose that insanity might not recur in its previous form were Chambers to be released from the Asylum. One of the epileptics under my care at the Asylum, who indulged freely in drink. ing, without displaying any indications of drunkenness, was subject to fits of grand mal attended by delusions and violent mania, with homicidal impulses, followed by temporary aphasia. The fits with the maniacal paroxysms and delusions did not appear so long as the patient, confined at the Asylum, was deprived of alcoholies. He was finally discharged, apparently sound in mind, but, a few weeks afterwards, he was returned, having a series of fits-status epilepticus-which lasted two days and ended fatally in meningitis.

The evidence of several witnesses shows that Mont. gomery had unequivocal paroxysms of epilepsy or mental derangement throughout the week preceding the homicide, confirmed, besides, by the testimony of Dr. Hammond, who says, that " before the homicide Mont. gomery was in a condition of permanent insanity." "That his delusions were the result of paroxysms of epilepsy," because Dr. Hammond knows that "they very frequently lead to such manifestations." At each one of these periods of delusional excitement, it seemed that Montgomery "had suffered from a paroxysm of epilepsy, either of the grand or petit mal." Notwithstanding these open assertions in court, when coming subsequently to express his opinion about the nature of the homicide, Dr. Hammond concludes, that "the circumstances of the affair are irreconcilable with the theory that the homicide was perpetrated during a paroxysm or an accession of epileptic mania."

Dr. Hammond, while testifying on behalf of the people, makes the following assertions: 
" That patients committing acts of violence during epileptic mania, have apparently no motive unless it is a false one."

"That he has never known a case of an epileptic fit or seizure where, during the continuation of it, the party will be spoken to, will answer, and then relapse into the same condition, and being spoken to again will answer and relapse again."

"That deliberation takes away the idea of an insane act."

"In temporary insanity from cerebral disturbance there is no disposition to resist the impulse, the person yields to it and strikes."

"When an epileptic has suffered from an attack, the mental disturbance continues frequently several days."

I will not assail this medical testimony which served to convict Montgomery by pointing out its striking contradictions. I only desire to remark upon the above assumptions made categorically before the court, and in direct opposition to well-acknowledged facts concerning the medico-legal bearings of epileptic insanity, and of insanity generally.

Although it may appear futile, I can not help noticing the very prevalent fallacy, that motive and calculation necessarily imply free-will or soundness of mind. I will look at the point only in reference to epilepsy, and will bring forward the following examples, which need no comments:

A young lady, patient of mine, subject to attacks of petit mal and grand mal, followed by temporary mental disturbance, having remained for several weeks free from either kind of fits, was suddenly seized with four attacks of grand mal, within two hours, on a Saturday morning, as she was about preparing herself to go to a theatrical matine?. She raved as usual after the fits, and had to be taken to her bed. She insisted upon being dressed to go out, 
without, however, making any attempts to get up, and her mother endeavored to quiet her by kind promises and arguments. She became calm, and asked her mother for a glass of water, which was handed to her; on holding it she siid : "Darling mother, let us case fighting; come, do sit by me in this chair," and, as the mother sat down to gratify her daughter's wish, she gave her mother a violent blow with the glass on the forehead, wounding her severely, exclaiming, "Now, now, I am satisfied. Don't let me dress and go to the theatre." Thereupon the girl continued in a state of excitement which lasted until next day. This patient has not preserved the slightest recollection of the above circumstance, its occurrence has been even concealed from her, as she became deeply affected when she first noticed her mother's wound, and was told that she had inflicted it when laboring under one of her fits.

I could also cite other instances in my own practice, where the existence of a real motive prompted the act of violence during epileptic insanity, but I will let Delasiauve speak, there being no higher authority recognized on epilepsy :

"H-C, who had been committed for insanity to Bicêtre, was again re-admitted after murdering his mother. At the trial, his counsel pleaded that he had been subject to transient aberration of mind, and listening to such a defence the court acquitted him. Epilepsy had not been suspected in his case, and at the asylum H__ displayed all the time complete lucidity, with the exception of short occasional excitements up to his death, occurring long after his return to the asylum. However, certain circumstances in addition to the account of one of his relatives, disclosing the previous existence of nervous paroxysms, led me to trace his momentary aberrations, and therefore his overt acts, to previous nocturnal fits. The court, convinced that the criminal deed was due to mental trouble, proceeded very judiciously by substituting administrative incarceration for capital punishment. Had the above existence of the attacks been known, the magistrates might have felt more satisfied as to the equity of their verdict."

"There was a peculiarity of a nature to raise objec. tions in this case, namely, that the murder had been perpetrated under the ruling of a jealous feeling, and even vou. XXIX-No. III.-F 
with an apparent motive, wherefore it was fair to infer that independently of the morbid excitement, it might have been prompted by a natural passion and become thereby punishable. This consideration, notwithstanding its weight, is far from carrying a decisive value. The instinctive perversions, consecutive to the epileptic fits, do not, as we have already seen, necessarily deprive the overt acts of epileptics of the mark of a voluntary determination. These patients are controlled in the midst of their passions by an appreciable motive, which has for them a reality; but, we should ask ourselves, if in a state of sanity such a motive would arise, and above all if it would be predominant enough to control reason. 'Thus, the motive and premeditation which seem under such circumstances to have dictated the criminal act are insufficient to establish peremptorily the integrity of free will, and consequently the existence of guilt."

"A young man, aged 28, committed to our hospital, eight months ago, affords a further proof of the above appreciation. Well-bred, educated, and belonging to a respectable family, he was condemned to two years' imprisonment for stealing a piece of dry goods firom his employer at the instigation of his mistress. He was transferred to Bicêtre on account of the repeated epileptic fits he had in prison. We then learned that he had been for five or six years subject to epilepsy, and it soon became manifest to us that the deed which caused his imprisonment must have been the result of his mental trouble. There are, indeed, apparently two natures in this individual, or rather his life displays two distinct phases. One inclosed within the circle of about a week, before or after the attack, when he is capable of every imaginable misdeed. At times, the delirium breaks out under the form of incoherent or furious mania, but, in other circumstances, it is reduced to a display of exaltation compatible with a more or less regular coürdination of ideas. J- shows himself irritable, imperative, gloomy, disposed to resort to violence, and intemperate. It is mainly at this time, while preserving sufficient lucidity to execute intentionally any act, that he fails, however, in the necessary discernment 
to judge of its morality, as also in the necessary self-control to abstain from doing it. During the other phase, in some sort normal, the character exhibits quite a contrast in its physiognomy with the preceding; it displays the qualities proper to a man in full possession of his senses, and free from any extravagancy. The moral transformation coincides otherwise with very manifest physical changes, to wit: the ordinary calm expression replaces a wild or melancholic cencentration of the features, lividity of the face and a kind of febrile movement."

"Lelut cites and comments upon an example analogous to the foregoing. Having discovered a prisoner at the Roquette, who had been several times convicted for numerous larcenies, and who had been subject to violent epileptic fits, attended with maniacal agitation, previous to the perpetration of the crime, Lelut does not hesitate to ascribe the latter to epilepsy. Such facts, says he, are frequent, and, if in this case, mania can not be considered as a persistent insanity on account of its shortness, one has a legal right to examine if such a serious and dreadful affection leares, in the intervals between the accesses, sufficient lucidity for the judicious accomplishment of acts and for responsibility." (Delasiauve, Epilepsie, pp. 486-488.)

To remove all doubts on the important point under consideration, Falret says: "The very great clearness of ideas which these patients (epileptics) occasionally display between their attacks, the words coherent enough which they pronounce, even in the midst of a great disorder of movement, the premeditation, the calculation, and the motives of revenge, that in some rare cases, con. trol the accomplishment of their misdeeds, might lead the magistrates to erroneous views on the morbid na. ture of such actions, if instead of regarding the whole symptoms of the disease, we confine ourselves, as is very often done, to discuss the motives and details concern. ing the special act which is the object of medico-legal examinatiou." 
Moreover, since facts are mightier than arguments, I may yet present the following remarkable instances, evincing unquestionably, that the acts of violence perpetrated by epileptics during their insanity may ac. knowledge a real motive. I copy them from the standard work of Legrand du Saule, "La Folie devant. les Tribunaux."

"Josephine D_, subject to epilepsy attended with imbecility, enticed a little girl to accompany her to the fields, where she choked her, having squeezed her to death with her hands, and stole her gold ear-rings. Josephine was acquitted by the Court of Assize at Laon."

"B. P., very gentle and very intelligent, was seized with epilepsy, at the age of fourteen, upon fright, and his intellectual faculties failed considerably, as it usually happens with such unfortunates when the fits become violent and repeated. Scandalized at the nicr, attire of $a$ young girl of fifteen, he struck her with a sickle he was holding, and almost beheaded her. B. P. was cleared from prosecution on the grounds of being affected with epilepsy and furious dementia."

"The woman Giraud had married a miserable man, who treated her indignantly, and who afterwards died at tic bagnio, having been condemned to penal servitude for life, being an accomplice in a crime of poisoning. She was, about three years before, struck on the right temple with a billy by her husband, and thereupon became subject to epileptic fits. From that time also, and mainly after her husband's imprisonment, which took place about the same date, this woman lived miscrably, being obliged to lispose of, or almost to give away the small stock of moveables she owned. She received for these objects the price stipulated upon, but she pretended the buyers had cheated her, or had not paid her in full, and she haunted them in her constant besetting way. She then gave herself up to stealing, under the pretense of making good her loss, and was on three occasions condemned by the correctional police. Finally she set fire to a neighbor's barn, whom she pretended to be her creditor, and who had testified against her in one of her trials for larceny. When the Mayor, who instituted the judicial proceedings concerning the above arson, called on her, she was found rolled up in the bed covers, but as the Mayor knew all the oddities of her character, he declined to examine her, feeling 
already satisfied that he would not obtain any sensible answer. She was arrested, a few days after, in an uninhabited house, where she had sheltered herself against the pursuit of the gendarmery."

Dr. Grenet, Physician to the Hospital at Barbezieux, commissioned by the Court to examine and report as to the mental condition of the woman Giraud, presented a very able and judicious report, with the following conclusions, preceded by these remarks:"Delasiauve, who is one of the authorities on the subject, says: ' Epileptic susceptibility does not only serve to help wicked propensities, but may of itself put them directly into play, by raising up or inspiring the idea of the misdeed, thereby driving fatally to its execution.' "In summary, since the maniacal excitement of epileptics disturbs to such a degree the soundness of the cerebral functions, that it may originate a confusion of the knowledge of right and wrong; and, as the woman Giraud has obviously displayed, on several occasions, symptoms of maniacal excitement, I do not hesitate to conclude :

" 1 st. That the woman Giraud is epileptic; her attacks, varying from simple absences to falling paroxysms, are very frequent.

" $2 \mathrm{~d}$. The criminal actions imputed to her are probably due to this disease. To guard against their recurrence, I believe that this woman should be placed under surveillance in a work-house."

On the strength of this report the Court of Bordeaux rejected the indictment. Let me, before disposing of the subject, bring to notice the following case, reported by Boileau de Castelnau, and worthy of being kept in mind whenever we are called upon to determine the limits of the responsibility of epileptics: 
"John Paul J-and Charles F- both convicts in the Central Prison of Nismes, had for a long time lived on bad terms with each other; on several occasions, and notably the 23d or 24th of June, 1850, they engaged in a passionate quarrel, during which John Paul addressed bitter and even injurious reproaches to Charles; but, up to that time they had not gone beyond a mutual exchange of words more or less foul or insulting. The 29th of June, during the forenoon, a new quarrel on some insignificant subject broke out between the two convicts, after which Charles was seized with an epileptic fit, a disease to which he was subject. During the fit, Charles seeing John Paul laugh, thought that he made a jest of his disease, and this belief tended not only to increase the irritation left on his mind by the previous quarrels, but also to complete the measure of his exasperation. Thinking that the knife he possessed was not suitable to carry out the plans of revenge he contemplated, he exchanged it for another belonging to an Arab, named Mahomed-ben-Ab, and who like himself was a prisoner. Shortly after this exchange the accused was seen twice sharpening the blade of his knife, with the file he had borrowed from another Arab. It was then about three o'clock in the afternoon. Towards five or half-past five o'clock, John Paul saw the accused advancing towards him, and noticed that he kept his hand in his bosom, where he seemed to handle some object. Charles, on coming up to him, asked why he made a jest of his disease, and as John Paul returned a negative reply, he proposed to him to fight. John Paul refused doing so, saying, that he did not want to fight a man like him, adding, that he excused him on account of his disease. After these words, John Paul was about turning to go away, when Charles suddenly rushed upon him, and drawing the knife from his bosom, rapidly inflicted six stabs on him. The most dangerous one was inflicted in the region of the heart, the internal mammary artery having been wounded; the first diagnosis of the physician was that the wound would probably prove fatal, a prediction which was not, however, realized."

I pass over the lucid examination of the facts, to present Boileau de Castelnau's conclusion :

"From the facts reported, Charles exhibited the characteristics of a derangement of the intellectual and affective faculties, induced by epilepsy, the attacks of which were frequent and of long standing. In one word, one 
can not avoid this dilemma: either Charles had been impressed in an unnaturally morbid manner by the insults of his antagonist, insults which superinduced an epileptic fit, during which he was again no less unnaturally influenced by the laugh of the same artagonist, both circumstances driving him to a wicked vengeance and making him (Charles) act the part of a madman; or again, Charles was impressed normally, but the consequences of his feelings were the acts of an insane man: coeteris consentibus 'the loss of moral liberty is incontestable.' He had no motive to kill John Paul, and to slay him by such a number of stabs."

The moral irresponsibility of Charles was pleaded most eloquently by Frederick Nicot, and the jury on finding Charles guilty of an attempt to commit wilful homicide on the person of John Paul, also admitted the extenuating circumstances. 'The Court, on the demand of the defence, lessened by two degrees the sentence, and Charles was condemne!l to six years' imprisonment. Boileau de Castelnau remarks: that the conviction was obtained upon subsidiary circumstances connested with Charles' antecedent3, it being manifest that the Court and jury were convinced, if not of the moral irresponsibility of Charles, at least of the want of control of his free will at the moment of perpetrating the crime.

Is it true, as stated by Dr. Hammond, that in a case of epilepsy, during the continuation of the seizure, the party will never answer if spoken to and then relapse into the same condition, to answer and relapse anew if being spoken to again? I will once more let the ex. amples speak for themselves in reply to this assumption, beginning by the case presented with so much pro. priety by Dr. Gray for the consideration of the Court. 
An epileptic, who had been fourteen months in the State Asylum at Utica, was subject to maniacal attacks, and for some time had been in the convalescent ward. One evening, when about to retire, he refused to take his medicine, alleging that it was poison, and looking at his watch, said: "I only have half an hour to live." He refused also to undress and go to bed. Dr. J. B. Andrews, [then the attending physician, to whom $I$ am indebted for these details,] being called, found him sitting by the bed with his watch in his hand. He instantly accused the doctor of poisoning him, and persisted in his assertions, until finally, he seized a chair and struck at one of the attendants who was sitting in the ward. He became boisterous and when asked to go to another ward, he vehemently declared he would not go. Several attendants were called, and on seaing them, he calmly and deliberately acknowledged that it was a useless attempt to oppose so many, but that on submitting himself against his will to their superior strength, he would have to be carried, which was done. He continued more or less excitable through the night, but appeared quiet the next morning. The next day when the Dr. was in the ward, the patient referred with regret to the occurrences of the previous evening and apologized for his conduct; then started down the ward and fell in a convulsive fit, fracturing the right ulnar bone. For three succeeding days he was quiet but moody, even made some pertinent suggestions as to the dressing of the fracture, took his medicine and food regularly, and seemed to appreciate his surroundings and condition. On the fourth morning upon awakening, without any noticeable change or recurrence of fits, he inquired why his arm was bandaged; the attendant told him because it it was broken. When the physicians came on the ward he asked them when and how his arm had been broken, declaring that he had no recollection whatever of any of the events from the first evening of excitement preceding the convulsive fit to that date, and was thereafter never able to recall any of the incidents happening during those four days. The foregoing principle could not be more completely upset than by this case, which is far from being unique.

One of the epileptics at the New York City Asylum, during a paroxysm of insanity succeeding several fits, struck and severely wounded one of the attendants simply for going to the rescue of another epileptic, who became so very violent that he had to be ramoved from the rest of the patients. I saw the above epileptic a few minutes after the assault in question; he was in a very ex- 
citable condition, but he talked to me, and rendered a very distinct account of his motive for assaulting the attendant: he even described very minutely the persons who took hold of him to bring him to the room where he was. He continued excited throughout the night and the subsequent day, after which he had a very vague idea of the circumstances just reported.

Another epileptic after his nocturnal attacks, harrassed by hallucinations, sees a man in the corner of his room, and begins to cry in great fear and distress. This condition continues sometimes for several hours. When spoken to he answers, often recognizes for a while the error of his delusion, and becomes comparatively quiet; but no sooner is he left alone, than he again falls into the above state of anxiety during which he has, in addition, short convulsive paroxysms.

Similar to Dr. Gray's case is the following under my own observation: A young man fell from the top of a ladder fifteen feet high, and became epileptic thereafter. He would while in conversation, stop suddenly, his head would drop, looking as if dead, but would regain consciousness in a few seconds, entirely unaware of bis condition. One evening, after one of these attacks, he went into the street, took a horse and buggy which he found in front of a house, rode over a mile and a half to his father's grave, pulled the flowers from the bushes planted over it, and brought them home to his mother, whom he invited to take a ride. Being asked where he procured the horse and buggy, he replied that he found them lost in the street. His mother directed him to go forthwith to a livery stable and there leave the horse and wagon that they might be returned to their owner. He started to do so, but left the horse and buggy for keeping at a livery stable as his own. When discovered by the owner, the transaction was looked upon as a larceny, thereby causing great mortification and annoyance to his family. The boy, however, could never account for his conduct, and completely forgot every circumstance connected with it. On another, more recent occasion, he left home after the attack, and while wandering through New York, he came across a sailor's agent, who engaged him to go as a sailor on board an English vessel starting for London. The agreement was signed and, after leaving almost all his pay and some of his personal effects, he embarked for England. The captain discovered from the start that he was no sailor, and finding him very flighty, exempted him from going to the top of the masts, and assigned to him very light duties. A few days after his departure, on coming out from his state 
of epileptic insanity, he expressed great surprise at finding himself on board a vessel bound for London, and completely ignorant how he came to be on board. The mother discovered through the police the departure of her son, and took the necessary steps to have him brought back. He has similar attacks of insanity after nocturnal paroxysms, or fits of petit mal as described above, but is quite rational and gentle in the intervening periods between the paroxysms, which render him very mischievous and inclined to be constantly running or wandering about. He is also given then to violence, and if he had committed a crime during any of the attacks here narrated, would he have been deemed responsible for it?

The following case, related by the celebrated Trousseau, is too important to be passed unnoticed.

"A young man, whilst on his way to the Palais Royal, in company with some friends, with whom he is going to dine, suddenly falls down on the "Place Louvois," but soon gets up again, and rushes on the passers by, striking them with violence. He is taken to the police station and for some time keeps insulting the soldiers who hold him, and spitting in their faces. Now had there been no witness of the epileptic attack which had preceded this extraordinary scene, and had not the physician who related the fact to me, interfered, the young man would have been tried for rebellion against the police authorities. It would be easily conceived, adds Trousseau, how difficult it is to arrive at the truth, when the epileptic and the victim of his violence are quite alone."

One of the most remarkable instances of the condition in which the mind may remain during epilepsy, has been communicatel to me by Professor John Ordronaux.

A German gentleman, aged 35, suddenly and during the high heat of one of our hottest summers, was attacked by a characteristic epileptic seizure, from which he soon recovered, but with evident symptoms of consecutive mania. Having been placed under medical treatment he continued to exhibit recurring attacks of epilepsy, the disease not yielding in intensity of seizures, although their intervals were beginning to be prolonged. This state of things continuel for about six months, when one morning immediately upon rising, he was seized with convulsions of great violence, 
which were repeated seven times, the whole period of the status epilepticus occupying about twenty minutes. From the last seizure he never recovered, but passed at once into a state of coma which lasted four days. At first there was strabismus of both eyes, with dilatation of pupils, cold, clammy skin, and feeble respiration. No involuntary evacuation occurred during the attack, nor was there ever any indication of paralysis of the sphincters. Iodide of mercury was administered internally, and epispastics applied to the spine. There was evidence that the former acted within twenty-four hours, as the strabismus disappeared; the skin also showed normal sensibility under the action of the vesicant, although in other parts of the body touching and pinching did not provoke apparent pain. During these four days the patient was fed regularly, was lifted from bed, and being put upon his feet, passed his urine freely on being told to do so, and a vessel presented to him, and even watched the process of micturition so as to avoid wetting himself. Being replaced in bed he would follow with his eyes persons moving about the room, and stare at any one who loudly pronounced bis name, for he could not hear ordinary sounds, and while his mind remembered automatically his name, he neither spoke nor evinced any expression of pain, or pleasure, or consciousness at the endearing appeals of his wife or mother, who hovered for hours about his bed side. It was evident that while his mind was enveloped in a haze of confusion produced by the shock of his epileptic paroxysm, it still worked clearly on a lower plane of introspection, sufficient to enable him to perform certain self-regarding acts, and even to regulate them by conventional standards, become habitual. But, outside of these, he knew no one individually, and had lost all conception of his relation to any being or thing distinct from himself. H乞 was in fact mentally cataleptic.

"Deliberation takes away the idea of an insane act," says Dr. Hammond. "In temporary insanity there is no disposition to resist the impulse." I can not see on what grounds rest these assertions of so great importance to the fate of Montgomery, for most, if not all alienists have now agreed that deliberation is not incompatible with insanity. "What must be thought," says one of our highest authorities on medical jurisprudence, "of the attainments of those learned authori- 
[January,

ties in the study of madness, who see in the power of the systematic design a disproof of the existence of insanity, when, from the humblest menial in the service of a lunatic asylum, they might have heard of the ingenuity of contrivance and adroitness of execution, that often characterize the plans of the insane?" And, the first example which falls under our eye in the standard work just quoted, is that furnished by Erskine, of a young woman indicted for murder, who was acquitted on the ground of insanity. "It must be a consolation," Erskine says "to those who prosecuted her, that she was acquitted, as she is at this time in a most undoubted and deplorable state of insanity ; but I confess, if I had been upon the jury who tried her, I should have entertained great doubts and difficulties; for although this unhappy woman had before exhibited strong marks of insanity arising from grief and disappointment, yet she acted upon facts and circumstances which had an existence, and which were calculated, upon the ordinary principles of human action, to produce the most violent resentment. Mr. Errington, having just cast her off and married another woman, or taken her under his protection, her jealousy was excited to such a pitch, as occasionally to overpower her understanding ; but when she went to Mr. Errington's house where she shot him, she went with the express and deliberate purpose of shooting him. She did not act under a delusion, that he had deserted her when he had not, but took revenge upon him for an actual desertion."-(Ray, Med. Jurisprudence of Insanity, Fifth Edition, p. 38.)

In making such a positive declaration in regard to deliberation, Dr. Hammond is from the beginning in direct contradiction with doctrines he has sustained elsewhere. When cross-examined by the District At- 
torney in the McFarland trial, Dr. Hammond asserted that-" the insane are very persistent in their revenge. I have known insane men occupied with the idea of killing their keeper for years, and finally do it." And, what were the circumstances attending the preparations to perpetrate the murder in McFarland's case? I avail myself of the graphic account given by my learned friend, the Hon. Samuel B. Garvin.

"When McFarland arrives at the City Hall Park he sees that the time has not yet arrived. The town clock stands there, illuminated, and he sees the time has not yet come, and goes into the office of Mr. Noyes, the lawyer. From there he goes to the Tribune office. He never speaks to a human being. He tells no story of his wrongs. He does not talk aboui his boy. He says not a word about Richardson. He does not inquire for Mr. Sinclair. He walks still and quiet, behind a desk, with a glass partition through which he can look, and which commands a view of both doors and nearly the whole office. What is he doing there at that time in the afternoon? It is almost dinner time, and he lives up town. He has no business on earth in the Tribune office at that hour, and yet there he is, waiting ten minutes, as two voitnesses testify, to see Richardson come in. Is this design? Is this premeditation? We see that he had motive for revenge, and anger and wrath against Richardson. Here is the plan being slowly developed by which his adversary is to go into eternity by the pistol of this man. He waits ten minutes. Richardson comes in; not having spoken to any one, McFarland leans forward, as one of the witnesses says, puts his pistol within three feet of Richardson, and fires it. The deed is done. What did he do? *** The next that is heard of him, about 8 or 9 o'clock in the evening, he is at the Westmoreland Hotel, and you have not heard one word on the subject of his pistol from that day to this."

If I have refreshed the reader's memory in regard to these details, it is not to argue the question of McFarland's insanity, but to show the length of the premedita. tion and its nature in one of the most typical cases of emotional insanity, as pronounced by Drs. Vance and Hammond who appeared on behalf of the prisoner. In 
this case two witnesses testified that McFarland was waiting ten minutes for his victim; whereas in Montgomery's case it is the weak-minded epileptic, Montgomery himself, alone, who, in his insanity, says "that be waited five minutes to kill his wife, because his temper got the upper hand of him." If such assertions are to prevail, if insanity, whether it be of an epileptic or of any other nature, must preclude every attempt at design or premeditation, we may as well reject every other prin. ciple equally confirmed by every day's observation of the insane, and by the numerous examples cited in the annals of insanity and medical jurisprudence in our country and abroad. Instances have been already presented here, of unquestionable epileptic insanity, where the design or premeditation to execute the deed has been apparent, but yet insufficient to render the individual accountable for the act. I may further cite the sad case of the epileptie who murdered Dr. Geoffroy, Superintendent of the Lunatic Asylum at Avignon:

The patient was subject to fits preceded by a feeling or dream, as he caHed it, starting from the abdomen to reach the brain. $\mathrm{He}$ had also vertigo and the fits were attended by furious delirium. On ose occasion, after a fit, he attempted to morder his father. On another he threw himself out of a window. He was quiet, orderly and of a gentle disposition. Two days before the murder, he met Dr. Geoffroy and, tendering the hand, he said to him, Union. The doctor, without paying much importance to the word, asked him if he belonged to any secret society, and thereupon kindly referred him to the assistant physician for anything he might desire. He became gloomy thereafter. Went to the kitchen, very restless, told one of the Sisters of Charity, that he was very unfortunate, and asked the Mother Superior for a prayer book; but as he was a protestant, she would not comply with his wishes without the previous authority from the Superintendent. Nothing remarkable was further noticed that day, and he passed a quiet night. The next day he went out of his ward; at noon called on the director, to whom he made the same remark addressed the previous day to Dr. Geoffroy, and held very little communication with any person 
throughout the day. On the following day he started early for the workshop; waited for Dr. Geoffroy in a vestibnle between the shop and the doctor's office, and as the doctor delayed his visit, he became impatient, and calling on the director he inquired after the chief physician, pretending to be sick. He was then informed that the doctor had just arrived and was visiting the wards. He waited at the door of the doctor's office, alone, in the position of a man suffering from a hurt, leaning on the left leg with the right hand concealed on the chest under his vest. He addressed himself to Dr. Geoffroy without changing his position. The dostor, without mistrust, approached, and no sooner had he stooped to examine the cause of ailment than he firmly surrounded the doctor's chest with his left arm, and suddenly stabbed him in the left side of the chest with a pair of shears, the blades of which he had fixed in a crossway by tying them firmly with a pockethandkerchief. Hs subsequently became furious, and the doctor died one hour and a half after.

As Dr. Laurent remarks in the interesting report from which the foregoing facts are abstracted: "This melancholy event furnishes a proof of the possibility of momentaneous distarbance that may originate from the mental state of that so-called ephemeral loss of freewill, a proof of the derangement of all that seems most steady within the sphere of affectivity, of the extent of such morbid phenomena, and the consequences they may entail. It shows an individual who had always displayed the best proclivities, industrious, gentle, obliging, grateful, and on whom evil propensities suddenly took the ascendant, driving him to commit such a hideous act as murder. In this instance, as already shown, the intervention of intelligence, the assistance of the intellectual operations, and of the will can not be denied. The combination of ideas that the patient conceived to obtain his end, the plan he devised to succeed, are elements of evidence which speak for themselves. Premeditation could not be denied here; but it would be impossible to admit any power of judgment. The struggle which 
took place within himself, and which he communicated to nobody, (a silence that may be ascribed to the natural pride and high ideas he entertained of himself,) had no more witness beyond an unsound reason incapable of reaching impartial decisions. The moral conscience being deranged, every resistance on its part to the most evil impulses was rendered impossible, and within the space of a few hours this lesion originated, to persist for a certain time and disappear, and to recur thereafter at intervals of variable length. Subsequently, this murderer would feel remorse and regret for the physician whom he loved and killed; while under morbid in. fluences, he would be on the contrary controlled by homicidal impulses and would approve of the crime he had committed. What a lesson does this dreadful event teach to specialists, to medical witnesses who are to guide the judgment of the courts, and to magistrates called upon to pronounce thenselves on the motives of the most extraordinary deeds!" (Baillarger, Archives Cliniques des Maladies Mentales et Nerveuses. Tome I., p. 222.)

As to the statement that "in temporary insanity there is no disposition to resist the impulse, the individual yields to it and strikes;" this testimony is completely nullified by numerous irrefragable cases. Everybody knows the frequency with which the insane will resist, not for days but for years, their impulses or delusions. It would be wearisome to detail the numerous examples contained in our standard works on insanity and medical jurisprudence. Esquirol, in his monograph on Homicidal Insanity, the first written and to this day a model one, establishes: "That all homicidal insane have a motive known or acknowledged, they obey a reflected or even a premeditated impulse," and on classifying them Esquirol forms 
a class embracing: "those who have no known motive, at least one can not suppose in them any motive imaginary or real; the unfortunates falling under this heading are driven by a blind impulse which they resist and escape from their evil impulses."

A patient of mine, recently dead, was affected with petit mal and nocturnal attacks since the age of puberty, the latter occurring unsuspected for a long time. He was besides subject to attacks of epileptic insanity, connected with the fits, and lasting from one to ten days. He would through them become aphasic, melancholic and driven constantly to kill his mother, when not beconing violent and boisterous. He went abroad expecting to overcome his disease by change of climate and surroundings, but returned unimproved. He would earnestly entreat his elder brother to avoid his sight while he was affected with his fit. Another curious feature in his case was, that he played the piano with great taste and skill, and during the fits of petit mal he would continue playing the most difficult pieces without ever an interruption, but would twist his head around indicating by this manner that he was seized with a fit of petit mal. When insane he would sit for hours playing the piano, having a succession of fits of petit mal, until he would rush on any of the bystanders, and so much bewildered and violent was he then that he had to be restrained. He died from meningitis after a series of fits.

Need I reproduce the cases so familiar, cited by Gall ?

An epileptic, while the fit was threatening him, experienced for several hours before its outbreak, an irresistible impulse to murder, and begged to be restrained and chained, and would cry out to his mother to save herself. He preserved his consciousness during the attack, and knew perfectly well that in committing a murder he became guilty of crime. When the fit was over he asked to be unbound and rejoiced that he had killed nobody.

A young woman would not bathe her child, or would not enter her husband and children's chamber if they were asleep, and would even throw the key of the door away, to prevent the possibility of re-entering it and heing overpowered by the impulse to kill them which would instantly seize her.

No less striking are the examples reported by Marc; one, that of Humboldt's servant, who preferred to leave Vol. XXIX.-No. III.-O 
his house, lest she would not resist the overwhelming impulse to tear Humboldt's child into pieces on being struck by the whiteness of its flesh on undressing it; and the other case, that of a young lady, who would entreat to have the straight-jacket put on, and to be closely watched until the motiveless homicidal desire, which she experienced sometimes for several days, would have passed; and, again the case of that chemist and poet who would request to have his thumbs tied together to prevent the sudden homicidal impulsessonce carried to execution in a murderous attempt against his attendant-and who finally died in a paroxysm of furious mania.

A very similar occurrence to this latter is illustrated by Bucknill, in a case under his observation at the Devon County Lunatic Asylum. The man, to avoid the murderous assault to which he felt himself urged, often requested to be locked in his bedroom, and still more frequently tied his own hands together with a piece of pack thread, which he could have snapped with the greatest facility, but which he said enabled him to resist the temptation. (On Criminal Lunacy, 2d edition; London, 1857 : p. 90.) In 1805 a man was tried at Norwich for wounding his wife and cutting his child's throat. He had been known to tie himself with ropes for a week to prevent his doing mischief to others and to himself. A man exposed to a sudden reverse of fortune was heard to exclaim, "Do for God's sake get me confined, for, if I am at liberty, I shall destroy myself and my wife! I shall do it unless all means of destruction are removed; and, therefore, do have me put under restraint; something above tells me I shall do it-and I shall."-(M. B. Sampson, Criminal Jurisprudence considered in relation to Mental Organization; London, 1851 : p. 9.) 
The case related in Knapp and Baldwin, (v. Newgate Calendar,) and quoted by $R_{x y}$, resembles in its prominent features one of nocturnal epilepsy, though not so presented.

A man after reading the indictment of Henriette Cornier, would awake suddenly in the course of the night with the thougnt of killing his wife, who was lying beside him. He left his wife's bed for a time, but within three weeks the same idea seized upon his mind three times, and always in the night. With the exception of light headaches occasionally, he had always bean well and free from pain. He was sad and troubled about his condition, and quitted his wife for fear that he might yield to the force of his desire.

A lady, says Falret, (Leçons Cliniques, 1864, p. 159.) began to experience, without any cause, a sudden overwhelming desire to ill-treat her aunt, whom she loved dearly, and after these fits of frenzy would become ashamed of herself and attempt suicide.

W not that a disposition to resist which prompted the man, cited by Guislain, to amputate his arm, to withstand the impulse to murder his wife, to which he was violently driven?

A young lady is seized with the evil impulse to kill her governess, to whom she is, however, deeply and gratefully attached. The idea oppresses her, increasing in degree, until she loses all rest. She takes care that knives, scissors, or even knitting needles, should be kept out of her reach; but she was not cured until after undertaking a journey through France and Italy, by the advice of Brierre de Boismont, who mentions the case. (Annales d'Hygiène et Médecine Légale, October, 1862, p. 457.)

In two out of the nine cases of homicidal mania, reported in Paul Jacoby's interesting thesis " on Impul. sive Monomania," the oft-repeated homicidal impulse 
[January,

could be completely overpowered. In one instance, there was a sudden return of discernment while the murder was being perpetrated, and the man upon inflicting a wound, not dangerous to a child, went and gave himself up as a prisoner.

Finally, I will allude to the case of the young student at the Seminary of Aix, who stabbed another student while asleep. He was placed under the observation of the celebrated Dr. Aubanel, of the Lunatic Asylum at Marseilles, and Dr. Cavalier, of the Asylum at Montpelier. Cavalier believed him to be in a condition approaching general delirium; and Aubanel was led to admit the existence of monomania. Upon a full and careful investigation of the facts connected with the case, Aubanel arrived among others at the following conclusions :

"That the homicidal propensity became at last so strong that after protracted resistance he was on the eve of yielding to it; it was then that he attempted suicide, and armed himself with a sword to carry the idea of murder into execution. The accused was not of sound mind for a long time before the murder, he was insane on the day and at the moment of perpetrating it, not forgetting that he premeditated the murler for ten or twelve hours. (Journal of Psychological Medicine, April, 1850, p. 25\%.) Delasiauve, in a most interesting report on this case, read before the Société Médicale du Pan. theon, takes a view altogether different from that of the alienists above named. Delasiauve states in a manner very forcible and bearing no less strongly on the case under consideration: "It is certain that on passing by an epileptic we elbow one who might be an assassin, and that epilepsy, through the fancies more or less delusional that it originates, furnishes a considerable share of the crimes reported by the daily press and ascribed to 
mental alienation. I should not, be surprised therefore, if such were the cause occasioning the homicide at Aix, because, in addition to the nervous susceptibility noticed during infancy, the reports of my colleagues point out, during the very year of the homicidal attempt, two convulsive fits of a suspicious nature." (eTournal de Médecine Mentale, Tome IX, p. 245.)

"When an epileptic has suffered from an attack, the mental disturbance continues frequently." In making this assertion Dr. Hammond retracted the opinion he expressed to the District Attorney for the City and County of New York concerning Jobn Reynolds, when Dr. Hammond emphatically said: "The disease, (epileptic mania,) is of remarkably short duration. There is not a case on record where it has lasted fifteen minutes, and it always comes on just after a fit. If Riy. nolds had had a paroxysm immediately before his entrance into the shoemaker's shop, whence he stole the knife, it would have been perceived by numerous persons in the crowded thoroughfare through which he passed." How can we bring the foregoing assertions face to face, and which of the two should be regarded as the correct one? The answer is of momentous importance, for on the faith of one, Reynolds was executed to vindicate the law, and on the strength of the contrary opinion sentence of death hangs over the head of the epileptic Montgomery!

Having referred to the most prominent points in evidence on the trial of David Montgomery, I must bring this review to a close. The responsibility of epileptics, or rather epileptic insanity, is a subject which seriously attracts the attention of alienists, and is frequently discussed in criminal casses. Delasiauve, Falret, Morel, Baillarger, Trousseau, and other no less high authorities, have described the characteristics of this condition, and 
made manifest its real existence; but, while objective symptoms and scientific principles, distorted or stretched to the utmost limits are allowed to prove the existence of transitory mania, or any other form of insanity, the clouded state of mind attending epilepsy, the positive phenomena of cerebral or larvated epilepsy, and the commission of a crime under such insane conditions, are rejected as a refinement of moral diagnosis. Delasiauve, on reviewing the question of Dangerous Lunatics, discussed before the Medico-Psychological Society of Paris in 1867, says: One is never more affirmative than on matters he is ignorant of :-we should not, therefore, be surprised at the theories advanced in reference to questions concerning epileptic insanity, which is particularly studied by few physicians. Bearing these facts in consideration, we should not be surprised at the light in which epileptic insanity is looked upon, and to find the proof of its existence left entirely dependent on the eloquence displayed in its advocacy, and above all on the degree of public feeling concerning the prisoner.

To those who deny the existence of epileptic insanity, namely, a more or less prolonged deranged condition of mind, either preceding, following or replacing the epileptic paroxysm, no argument could be presented of more force than the practical study of epileptics. I am very far from thinking that every epileptic should be considered insane or irresponsible, any more than I would regard every individual as an epileptic who has had a single epileptiform convulsion. As I have before asserted, chronicity to my mind is as essential as any of the other characteristic phenomena of epilepsy; and I would refuse exculpating any overt act attributed to epilepsy, unless committed in a clear relation with the attacks, or while the perpetrator exhibited signs of cerebral epilepsy. 
There is no period or limit fixed for the disturbed condition of mind following the epileptic attacks. The Roman laws, in Zacchia's time, declared epileptics irresponsible, $i$. e., having no free-will, for three days after the attack. No provision of the kind has ever been made by the French Code, nor by any other laws, excepting certain local ones in Germany, according to Boileau de Castelnau. That the limit of duration within which epileptic insanity was encircled by the Roman legislators, was a very narrow one, over and over again contradicted by experience, is a fact mainly accounting for the little attention which has usually been paid by the French courts to the above article of Roman medical jurisprudence.

Duration, frequency, and the hereditary nature of the attacks, are the most important etiological elements of epileptic insanity. The relations between the former conditions and the latter are manifest by the statistics of those who have studied the subject practically and by my own. There is one circumstance, ordinarily misunderstood, namely, the meaning of unconsciousness in regard to the different phases of the epileptic malady. It is usually supposed that unconsciousness means insensibility; and that, therefore, epileptics should be in a state of inability to speak or answer, or to notice what transpires around them during their seizures, and hence the prejudice against admitting that criminal epileptics have no mental perception of deeds perpetrated by them in a condition of epileptic insanity. The fallacy of this belief is quite obvious, for, the same condition is not exclusive to epilepsy, but is generally common to other forms of insanity. Normally we can not control reflex actions, whereas in epilepsy the reflex faculty of the nervous system is carried to the highest morbid pitch, and hence the extremely violent 
and uncontrollable reactions peculiar to the disease. In epileptic insanity reason goes astray; the feelings, perceptions, and will of the patient are deranged; there is, indeed, a nervous susceptibility, a condition of extreme general hyperæsthesia, ready to react on the least moral or physical incitation; and yet we can not say that the individual is completely deprived of his free-will or discernment any more than in any other kind of insanity. As Albert Lemoine asserts: "We should avoid to affirm or even to suppose, that the mental state of a madman consists in his completely losing full possession of his faculties. He who has lost his free-will is undoubtedly insane, and his insanity reaches the highest degree; but it does not follow therefrom that a patient must necessarily appear divested of all free-will to be pronounced insane. Even if insanity cousists of a derangement of the will, it is far from being a settled question, but, on the contrary, one yet to be decided, whether full possession of our faculties might not coëxist to some extent with insanity, and to what degree or under what circumstances-as in organic diseases - the disorder of sensibility, the delirium of the intelligence might lessen or keep under, without suppressing entirely, the free-will of the insane."-(I'aliéné ilevant la Philosophie et la Société, p. 272.)

In regard to the changes undergone by the moral and intellectual disposition of the epileptic, they take place generally even before insanity can be confidently declared. Esquirol points them out distinctly and remarks-that epileptics have exalted ideas, that they are very susceptible, irascible, obstinate, difficult to please, capricious, odd, every one possessing some peculiarity of character. Calmeil states, that all epileptics not yet insane are very irascible, very impressionable, and disposed to false interpretations: that which scarcely 
moves a man of ordinary susceptibility causes in them a feeling of profound trouble. After alluding to the opinion of the above and other authors, Baillarger declares: "That epilepsy, before leading to complete insanity, produces very important modifications in the intellectual and moral condition of certain patients; these sufferers become susceptible, very irritable, and the slightest motives often induce them to commit acts of violence : all their passions acquire extreme energy." (Ths Responsibility of Epileptics. Medical Critic and Psychological Journal, Vol. I., p. 510.) Delasiauve says: "Epilepsy in particular exposes people to dangers the gravity of which is not sufficiently appreciated.

One is never in safety with epileptics." (On Dangerous Lunatics. Journal de Médecine Mentale, Tome X., p. 20.) Nothing, however, gives a more comprehensive idea than Legrand du Saule's words: "Everything is contradiction with the character of epileptics; nothing could be equal to the frequency, rapidity, and excessive change of the ,contrasts they exhibit." ( $L a$ Folie devant les Tribunaux, p. 367.) I think that I need insist no longer on the deep mental and moral change which epileptics generally undergo through the active progress of their malady. As intellectual impairment is admitted by all authorities on the subject, which by degrees more or less imperceptibly undermines the instincts and emotions, and draws the individual towards depravity, therefore epileptics should always be looked upon as dangerous. And, because Mahommed, Socrates, Caligula, Cæsar, Charles the Fifth, Napoleon Buonaparte, and other geniuses were subject to epileptic paroxysms, as history tells us, are we therefore forced to conclude, that epileptics should not be considered irresponsible, when displaying evidences of epileptic insanity? One of the 
most demented epileptics under my care, with an in. herited predisposition to the disease from his father and mother's family, and epileptic since his infancy, exhibits for a day or two a remarkable remembrance of events that happened long before, and talks in a bright man. ner, which disappears upon the return of his nocturnal fits. During this stage of his malady, he violently strikes those who go near him, if his wishes are opposed; he also becomes very mischievous, and has an obstinate determination to evade vigilance and to run away from the house. Should he be judged in these lucid intervals-when his morbid impulses render him so dangerous-more responsible than in his harmless habitual state of complete dementia? There is a broad and obvious difference between a man who has had rare or even num. bers of epileptic fits at long intervals during his life, and one whose physical and moral constitution is deeply tainted by a hereditary predisposition to epilepsy, who becomes impressed by this latter in a prolonged and frequently repeated form, and whose weak intellect-in regard to morbid impulses-is, to all appearance, in the words of McIntosh, "little deranged, while lurking in the secret recesses of the brain, there lies some sweeping moral defect or perversion, which only requires its peculiar stimulus to be excited into active mischief." (On Morbid impulse. Medical Critic and Psychological Journal, Vol. III., p. 102.) To the second class belongs Montgomery.

I have already shown that design, or premeditation, is not any more incompatible with epileptic insanity than with any other form of insanity, and I will further assert with Devergie, that: "Intelligence and sagacity are not sufficient to enable one to judge if a brain be healthy or diseased; it is necessary, in addition, to have studied individuals suffering from every 
variety and form of insanity." (Where does reason end or mania begin? Psychological Journal, Vol. 12, p. 358.) Then again, as Boileau de Castelnau establishes so categorically; "Premeditation may bear the mark of criminality, in this sense; it may have been conceived in a moment of calm and of more or less un. fettered exercise of the intellectual faculties, but yet, the deed may have been perpetrated under the pressure of a complete loss of moral freedom, because the individual, deficient in resolution at a moment distant from the attack, may yet have found, during the transitory insanity that precedes or follows the fit, a morbid energy sufficient to carry his design into execution. Do we not often see threats repeated without effect, until a fit of drunkenness, of anger, or of transitory madness supervenes, and they come to reality? It becomes, therefore, indispensable to inquire whether, at the moment of the deed, the epileptic was or was not in one of those stages so common with those patients, whether it did not happen a short time before or after the fits, whether the attacks did not recur more frequently than ordina. rily." (Op. cit. p. 44.) It can not be needful that we should add, how requisite it was to have carefully considered in their true light, all these circumstances in Montgomery's case, while there is no necessity either tc repeat, that the evidence adduced medically as well as legally, was ignored in its most cardinal points by the physicians examined for the prosecution, whose opin. ions we are, therefore, bound, in justice to the criminal, to question, as immaterial in many respects, and resting on an unwarranted assumption as to facts and scientific principles.

One word about the absence of some objective signs in Montgomery-remarked by Dr. Hammond. Physical signs can scarcely be held sufficient to diagnos- 
ticate any form of insanity, and they possess therefore no intrinsic medico-legal value. "Much reliance, as Bucknill truthfully says, is not to be placed upon any one, or even upon several, of the physical signs of nervous disturbance. They have a scientific, but scarely a diagnostic value. They may serve to direct the inquiries of the physician, or even to confirm his opinion founded upon other data; but, standing by themselves, they are of little importance in the diagnosis of insanity." (Psychological Medicine, p. 345.)

The researches of Buchut, Duguet, Hughlins Jackson, C. Allbut, Noyes, and my own, show, that although the opthalmoscope discloses retinal changes in some cases of epilepsy, they are far from being constant or uniform. I furthermore agree with Dr. Noyes, that we are not yet clear in regard to the significance to be attached to the pulsations of the veins upon the disc, taken as a sign of cerebral anæmia, and made much of in epileptic cases to determine the vascular state of the brain. Nor is it clear that Montgomery possessed a normal sensibility, since, as Dr. Hammond testifies, there was a slight want of sensibility in the left side of the body, ordinarily endowed with more acute sensibility than the right. Giving foremost importance to physical signs, this peculiarity should favor rather than discountenance the assumption of dementia in Montgomery's case, according to the observations made by Dr. Hammond in reference to the lessened state of sensibility in dementia. Possibly the phenomenon may also recognize its origin in the disease of the right internal ear extending to the brain,-but this is a mere conjecture of secondary importance to the question of epileptic insanity at issue.

The foregoing details have been intended to specify clearly and briefly, within the restricted limits of this review, the only criteria that should guide us in estab- 
lishing the criminal responsibility of Montgomery. I have strictly confined myself to consider the facts in evidence, without stretching their significance, and their careful examination leads me to conclude, that; in Montgomery's case, the murder was committed, if not directly when laboring under a fit, most certainly in one of the rapid transitions from the reap. pearance of reason to the violence or fury, peculiar to the condition of epileptic insanity through which Montgomery had gone from the Monday previous to the homicide, until the Sunday when the murder took place. No feeling can arouse greater delusions than jealousy, and no brain can be more susceptible to its evil influence than that of an epileptic. What transpired during the night of Saturday, after Montgomery and his wife arrived home, when all was peace and harmony between them, and she had been talking to him sitting on his knee; when, as Montgomery says, they even had sexual intercourse, is, indeed, a mystery to all. Why, therefore, should Montgomery have preferred the bright morning to the dark silent hours of the night to accomplish his design, if he really had premeditated murdering his wife? $\Lambda$ nd how could she so confidently and unconcernedly go to sleep during his momentary absence, if they had actually quarrelled so angrily in the morning; for, the evidence indicates that she was struck while sound asleep. It is not denied that Montgomery suffered from nocturnal epilepsy, whereas it is not uncommon for fits to occur upon the rising of the patient, and, therefore, it may be fairly assumed that Montgomery might have had an epileptic seizure on getting up, before or after he was cutting the kindlings for the fire. Furthermore we find on behalf of this assumption, that when he was seen running to the barn immediately after the murder, Montgomery was partially dressed, 
one of his suspenders hung over his shoulder, and the other down by his side. It has not been disproved that the ax remained in Montgomery's room from the Thursday night, between two and three o'clock, previous to the homicide, at which time he took it from his father's house to cut some kindlings to warm the baby's milk. I do not believe that any stress can he laid upon the five minutes that Montgomery looked at his wife, as he said he did, before he struck the deadly blow on her head. Five minutes is a meaningless, familiar expression, which refers to any indefinite short duration of time, and, on this account, it might have been as well five seconds as five minutes, since Montgomery was by no means in a condition to estimate how long a time it took him to obey the morbid impulse to strike his wife. Montgomery did not go to meet his younger brother in the street, but the latter saw him run to the barn in a bewildered state, with a razor in his hand, and assisted by his father, succeeded in preventing his attempts to cut his throat. The kiss Montgomery gave his wife after slaying her, his subsequent deportment, the remark he made to James Hunter, whom he met on his way to the police station, his answers and requests to the police officers, the conversation with the chaplain of the jail, and afterward with John F. Rothgale and Mr. Benjamin,-all occurring within the two or three hours after the homicide, are typical of the condition of epileptic insanity then exhibited by Montgomery. His intellect. ual faculties operated by sudden starts, were in a state of instability incited by every idea that suggested itself to a brain in the highest morbid degree of susceptibility, superinduced by the previous several fits, after which he returned to a calmer or more natural condition on coming out of the sleep he had on Sunday afternoon. Thereupon, the recollection of the recent events, and of 
the tragedy in which he played such a principal part, entirely disappeared, and the murder continued from that moment wholly unaccounted for and ignored by David Montgomery.

Sleep always marks the transition from the epileptic seizure to the normal state of mind, whether the fit be a genuine paroxysm, or one of cerebral epilepsy. I may assert on personal observation, that in every instance complete recovery of the intellectual faculties is heralded by sleep, even if mania has continued for several days. When mania attends the convulsive fits the patient jumps from the spasmodic stage directly into that of mental excitement, without sopor, or any intermediate period of sleep between the two. I do not recollect any instance where the contrary fact, namely, passing into a sound condition of mind during wakefulness, has taken place in epileptic insanity. It is unnecessary to point out the medico-legal bearing of this phenomenon.

In order to leave no important point unnoticed, let me remark that, the marriage of young Montgomery, a boy, sober, industrious and religiously brought up, to a vile prostitute, indicates anything but soundness of mind; while the strong hereditary tendency to insanity permeäting his family, and the existence in him of internal otitis, since his infancy, in addition to the severe injury he received on the head, are also circumstances of great moment to help us to judge the medico-legal question at issue in Montgomery's case. It is plainly manifest by the report of the commissioners that the epileptic malady-petit mal and dementia-continued after the homicide.

Finally, two circumstances deserve special notice. In Sept., 1871, while in jail, Montgomery had an epileptic fit in the presence of his brother A. G. Montgomery, 
Mr. McKebben and other persons. The fit was a severe one; thereupon Montgomery fell into a restless kind of sleep, hecame stupid for three days, and remained unconscious of his having had a fit.

The 22d of last August, about 8 o'clock in the morning, I accompanied General J: H. Martindale to visit Montgomery at the jail in Rochester. We found that Montgomery was just getting up. I was left alone with him in the cell, and examined him for about. threequarters of an hour. He lid not take particular notice of General Martindale, whom he had not seen for several weeks. His bodily condition was good, but his hands and feet were quite cold and very purple. The marks in the neck were slightly apparent. The face was congested, with a stupid expression; eyes encircled by a deep bluish hue, pearly color of the conjunctiva; pupils very much dilated before the bright light of the sun; and the right pupil, irregular in shape, much larger than the left; lips puffy. Several small petechiæ were around the eyes and in the neck. Slight sero-purulent discharge from the right ear. Tongue slightly coated, with an ulceration in the left side. Pulse 104, and soft. Respiration 13 to 14 to the minute. Action of the heart irregular, soft murmur at the base. Com. plained of pain in the right temporal region, and of severe healache. Did not sleep from headache on the night of Wednesday - two lays before our visit, but was not aware of having had any fit. His pillow had a large light, bloody stain. Did not wet his bed; but had frequent seminal emissions in his sleep. The night previous-" "had a fight with a cartman who was driving at him;"-and "his child came to see him."Did not know whether his wife was dead or alive, and wanted to go to her:-Does not remember having killed her. On the night of Saturday before the homicide, 
he went to bed on good terms with her; had not slept with her for a week; had sexual intercourse with her after retiring; was disturbed by the baby late at night and could not sleep from headache. Did not go to his father's house for the ax, he had kept it in the room, and went down stairs on Sunday morning to get kindlings for the fire. Does not recollect what occurred afterwards; nor how it happened that he was brought to the jail. His wife was sleeping when he came down; had no quarrel with her that morning, "she was sleeping." He gave all these replies to my questions, but did not open any conversation, was slow in his an. swers, and would laugh in a silly manner at many of my inquiries. The state of his mind, his stupid appearance and the general expression of his countenance indicat $\ell$ most positively that he had a recent nocturnal attack, probably on Wednesday night, and I said so to General Martindale. There was no doubt as to his being then demented and actually suffering from epilepsy. I should also believe that, in addition to the fit wit. nessed by his brother, and to the one the traces of which were so plainly to be seen when I visited him, Montgomery must have had, during his incarceration, other unnoticed nocturnal attacks.*

* Since writing the above a Lunacy Commission has been appointed by Gov. Hoffman, consisting of Prof. John Ordronaux, Dr. J. M. Cleaveland, Supt. Hudson River Hospital for Insane, and Dr. Jacob S. Mosher, Surgeon General, of New York. After a careful examination of Montgomery, the Commission declared him insane, and he has since been sent to the State Asylum for Insane Criminals, at Auburn.

M. G. E. 